\title{
The epithelial-mesenchymal transition and the cytoskeleton in bioengineered systems
}

\author{
Susan E. Leggett ${ }^{1} \mathbb{D}$, Alex M. Hruska ${ }^{2}$, Ming Guo ${ }^{3}$ and lan Y. Wong ${ }^{2^{*}}$ (e)
}

\begin{abstract}
The epithelial-mesenchymal transition (EMT) is intrinsically linked to alterations of the intracellular cytoskeleton and the extracellular matrix. After EMT, cells acquire an elongated morphology with front/back polarity, which can be attributed to actin-driven protrusion formation as well as the gain of vimentin expression. Consequently, cells can deform and remodel the surrounding matrix in order to facilitate local invasion. In this review, we highlight recent bioengineering approaches to elucidate EMT and functional changes in the cytoskeleton. First, we review transitions between multicellular clusters and dispersed individuals on planar surfaces, which often exhibit coordinated behaviors driven by leader cells and EMT. Second, we consider the functional role of vimentin, which can be probed at subcellular length scales and within confined spaces. Third, we discuss the role of topographical patterning and EMT via a contact guidance like mechanism. Finally, we address how multicellular clusters disorganize and disseminate in 3D matrix. These new technologies enable controlled physical microenvironments and higher-resolution spatiotemporal measurements of EMT at the single cell level. In closing, we consider future directions for the field and outstanding questions regarding EMT and the cytoskeleton for human cancer progression.
\end{abstract}

Keywords: Actin, Vimentin, Cytoskeleton, Collective migration, Extracellular matrix

\section{Background}

The epithelial-to-mesenchymal transition (EMT) occurs when tightly connected epithelial cells acquire a migratory mesenchymal phenotype during embryonic development, wound healing, and disease $[1,2]$. Historically, EMT has been associated with a profound reorganization of the cytoskeleton in order to weaken cell-cell attachment and strengthen cell-matrix adhesions [3], and was first observed by Elizabeth Hay in response to instructive cues from the extracellular matrix [4]. Indeed, tumor invasion and drug resistance are associated with dysregulated extracellular matrix, with aberrant matrix deposition and remodeling resulting in enhanced stiffness [5]. Cytoskeletal elements are well established as EMT

\footnotetext{
*Correspondence: ian_wong@brown.edu

${ }^{2}$ School of Engineering, Center for Biomedical Engineering, and Joint

Program in Cancer Biology, Brown University, 184 Hope St Box D, Providence, RI 02912, USA

Full list of author information is available at the end of the article
}

biomarkers, particularly intermediate filaments such as keratin (in epithelial cells) and vimentin (in mesenchymal cells) [6]. Nevertheless, the functional importance of EMT and associated cytoskeletal changes remains poorly understood, particularly for cancer progression in humans [7]. Recent bioengineering innovations have enabled biomimetic assays and higher-resolution measurement tools to elucidate EMT at the single cell level over space and time.

Classical cell migration assays are based on experimental conditions that can artificially bias towards epithelial or mesenchymal states [8]. For example, "wound-healing" assays occur on rigid tissue culture plastic, based on the collective migration of tightlyconnected epithelial monolayer sheets [9]. Alternatively, Transwell (Boyden) assays are based on a plastic microporous membrane, which cells must traverse as individual cells, impeding collective migration [10]. Tridimensional (3D) culture conditions, based on embedding cells within a compliant biomaterial, represent a

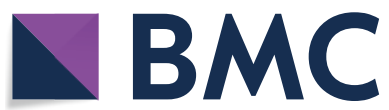

(c) The Author(s) 2021. Open Access This article is licensed under a Creative Commons Attribution 4.0 International License, which permits use, sharing, adaptation, distribution and reproduction in any medium or format, as long as you give appropriate credit to the original author(s) and the source, provide a link to the Creative Commons licence, and indicate if changes were made. The images or other third party material in this article are included in the article's Creative Commons licence, unless indicated otherwise in a credit line to the material. If material is not included in the article's Creative Commons licence and your intended use is not permitted by statutory regulation or exceeds the permitted use, you will need to obtain permission directly from the copyright holder. To view a copy of this licence, visit http://creativecommons.org/licenses/by/4.0/. The Creative Commons Public Domain Dedication waiver (http://creativeco mmons.org/publicdomain/zero/1.0/) applies to the data made available in this article, unless otherwise stated in a credit line to the data. 
promising alternative for investigating invasion and EMT $[11,12]$. In particular, mammary epithelial cells cultured in reconstituted basement membrane (i.e. Matrigel) recapitulate differentiated tissue-like architectures with lumens and cell-cell junctions, which progressively disorganize and disseminate in response to aberrant microenvironmental cues [13]. More recently, engineered biomaterials [14] and microfabricated devices [15] have provided increased control over material stiffness, degradability, and architecture. These controlled microenvironmental conditions may provide new insights into how cell-matrix interactions mediate collective and individual migration phenotypes.

Phenotypic heterogeneity and plasticity are defining features of cancer cells, and remain challenging to investigate using bulk analyses at endpoints [16]. EMT is believed to occur rarely in a small subpopulation of cells, which may be overlooked without comprehensive single cell measurements. Live cell imaging with high spatial and temporal resolution may enable new insights into molecular and cellular-scale dynamics during invasion and EMT [17]. For instance, cytoskeletal protrusions are particularly important for directed migration, and cells can appreciably deform their surrounding ECM [18]. In turn, cells may undergo substantial deformations to traverse ECM, which may be facilitated by a more compliant cytoskeleton. It has been further hypothesized that cancer cells are significantly softer than their nontransformed counterparts, particularly in the context of stem-like states that express vimentin [19]. Overall, there is increased interest in subcellular resolution of cell-matrix adhesions [20], as well as collective behaviors mediated by cellcell junctions [21].

Here, we review recent developments in EMT and the cytoskeleton in cancer (particularly intermediate filaments) enabled by biomimetic materials and higher resolution measurement technologies. We focus on publications within the last 5 years, and emphasize potential links between the mechanobiology of the intracellular cytoskeleton and the extracellular matrix. For more comprehensive treatments of EMT in cancer, we refer readers to other recent reviews on this topic $[1-3,7,22]$. We first provide a brief primer into the biochemistry and mechanics of the cytoskeleton as well as operational definitions for EMT. Next, we consider EMT-like behaviors during collective and individual migration on planar substrates. We further consider the dynamics of vimentin and EMT in 2D monolayer and $3 \mathrm{D}$ matrix culture. We then address the effect of submicron topographies ("2.5D") and compliant 3D matrix on migration and EMT. Finally, we provide our perspective on EMT and cancer metastasis, as well as future directions for the field.

\section{Functional definitions for the epithelial-mesenchymal transition}

Classically, EMT has been understood as a multifaceted program of phenotypic changes that cause an epithelial cell to acquire mesenchymal characteristics, including altered polarity and cytoskeletal organization [22]. EMT programs can be activated by inflammatory stimuli including growth factors (e.g. TGF- $\beta$, HGF, EGF, WNT), hypoxia, and extracellular matrix components (e.g. collagen I), which act through developmental transcription factors (e.g. SNAIL, SLUG, TWIST, ZEB1/2, and E2A proteins, E12/E47) to repress E-cadherin expression and induce mesenchymal gene expression (Fig. 1a) [1] . Small, noncoding single-stranded RNAs (microRNAs or miRNAs) work in concert with transcription factors to regulate the promotion or repression of EMT signaling networks in a context-dependent manner [1]. For instance, the well-studied miR-34 and miR-200 miRNA families serve dual roles as tumor and EMT suppressors though the formation of double-negative feedback loops with SNAIL and ZEB1/2, respectively [23]. EMT may be activated to varying extents, yielding a diverse spectrum of intermediate states ("partial EMT") and may be reversible through mesenchymal-to-epithelial transitions (MET). Altogether, these dynamic processes have been more broadly defined as "epithelial-mesenchymal plasticity" [2].

Epithelial tissues consist of sheet-like architectures that cover body surfaces and hollow organs (e.g. skin, breast, lung, colon, prostate, etc.) [24]. Cancers associated with epithelial tissues (i.e. carcinomas) represent the most common type of cancer in humans [25]. Epithelial cells typically organize into tightly-connected multicellular layers with strong cell-cell junctions on both lateral sides (e.g. tight junctions, adherens junctions, and desmosomes), which maintain apicobasal polarity and limit motility (Fig. 1b, e). In turn, these junctions are linked to the cytoskeleton, including a circumferential F-actin belt as well as keratins [26, 27]. Cortical F-actin is also distributed at the periphery of epithelial cells, while keratins form an extended network from the nuclear envelope out to the cell membrane. It should be noted that this cytoskeletal organization is maintained by cell-matrix adhesions anchored to the basement membrane.

YAP/TAZ transcriptional activators have also emerged as sensors of these cell-cell and cell-matrix interactions, which can trigger EMT [28] as well as stem-like phenotypes [29]. YAP/TAZ are part of the Hippo pathway, which is a key regulator of tissue homeostasis via growth control [30]. For instance, high cell densities or soft 
a

Epithelial:

apical-basal polarity

cell-cell junctions

E-cadherin

keratin

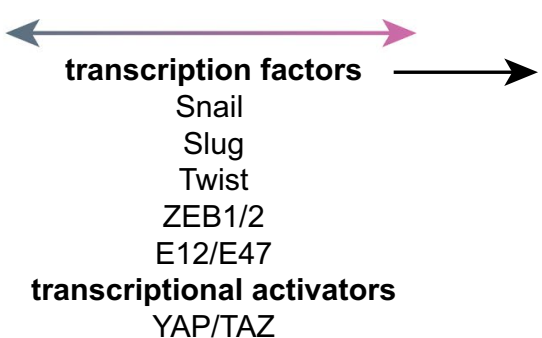

Mesenchymal:

front-back polarity

cell-matrix adhesions

actin polymerization

vimentin

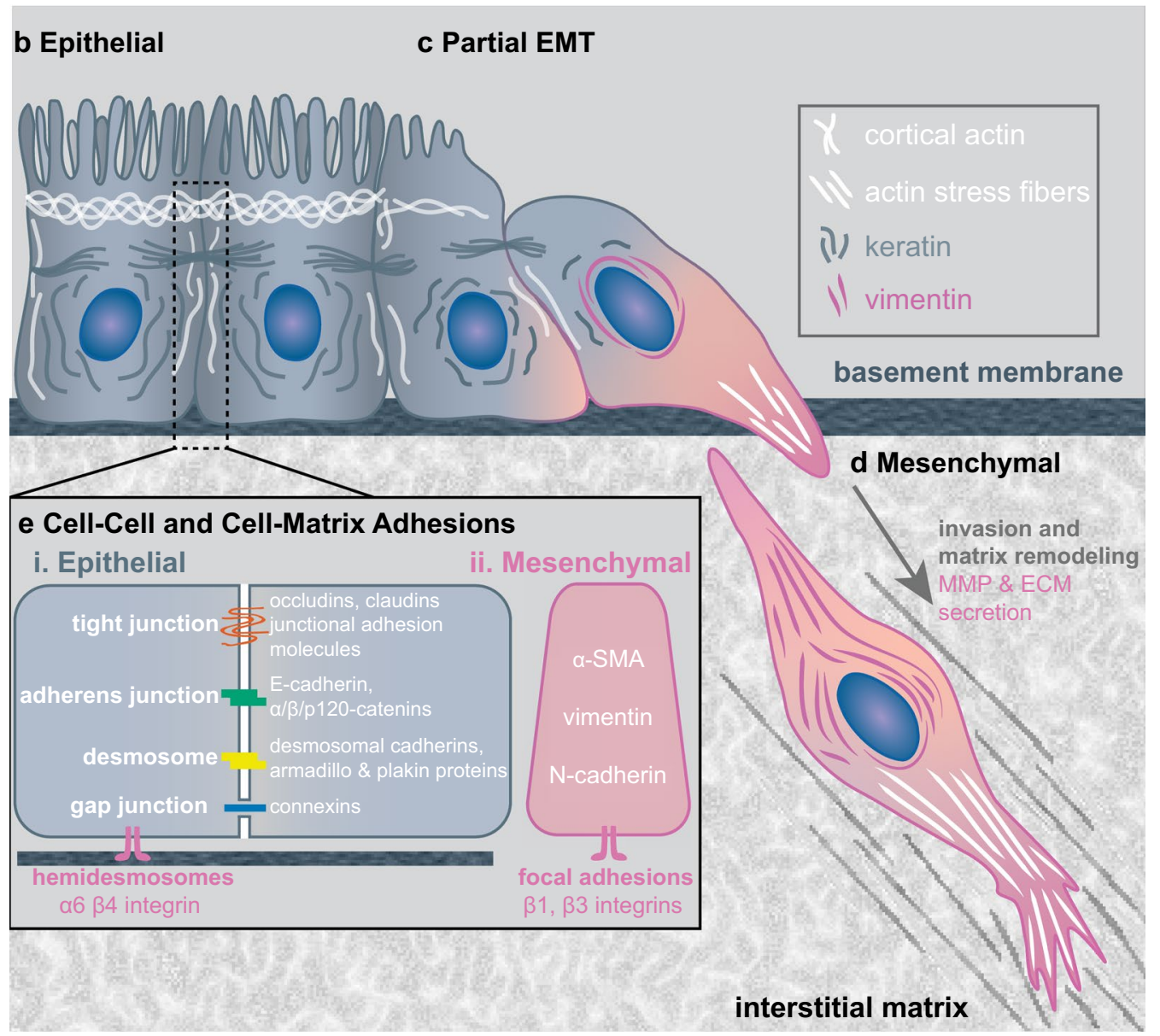

Fig. 1 Schematic of EMT progression. a Common features of epithelial and mesenchymal phenotypes, as well as transcription factors that drive EMT. Artistic representation of cell morphology and cytoskeletal organization for $\mathbf{b}$ epithelial, c "partial"EMT, and d mesenchymal states. e Detailed depiction of cell-cell and cell-matrix adhesions

matrix are associated with inactive YAP/TAZ via localization in the cytoplasm or controlled degradation, which prevents proliferation in normal cells [29]. However, lower cell densities or stiffer matrix permits increased actin contractility, resulting in active YAP/TAZ via translocation to the nucleus to promote proliferation. Dysregulation of YAP/TAZ signaling is associated with loss of sensitivity to mechanical cues and uncontrolled proliferation in tumors. Moreover, YAP/TAZ activation has been associated with enhanced migration, drug resistance, anoikis-resistance in circulation, metabolic adaptation, and metastatic colonization (reviewed in [31]). YAP/TAZ further exhibit crosstalk with growth factor signaling (e.g. WNT, TGF- $\beta$, Hedgehog, EGF, Notch), as well as with various ligands associated with G-protein coupled receptors (GPCR) [30]. YAP/TAZ activation occurs dynamically in response to external mechanical and chemical cues, and an improved understanding of this signaling pathway requires the capability to perturb cells with a 
time-varying stimulus while reading out the phenotypic response over time.

Collective cell migration is increasingly recognized as a crucial mode of cancer invasion, and is associated with partial connectivity between migratory cells [8]. So-called "leader cells" retain some cell-cell junctions at their trailing edge, which allows them to mechanically coordinate the migration of "follower" cells (Fig. 1c) [32]. This phenomenon has been associated with a "partial" EMT, since cells may co-express epithelial and mesenchymal biomarkers (e.g. E-cadherin, keratins, vimentin), although operational definitions remain unresolved [7]. It should be noted that analogous processes occur during collective migration and EMT in embryonic development, which may provide useful biological insights [33].

Finally, a complete EMT occurs when initially epithelial cells undergo cytoskeletal organization with a loss of apicobasal polarity and gain of front-back polarity (Fig. 1d) [22]. In particular, cells weaken their cell-cell junctions and redistribute $\beta$-catenin, while forming actin-rich protrusions at the leading edge [3]. Moreover, cells gain expression of the intermediate filament vimentin, which is also distributed throughout the cell interior and protects the nucleus [34]. Classically, EMT is associated with total detachment of individual mesenchymal cells that exhibit elongated morphology and expression of vimentin, N-cadherin, and $\alpha$-smooth muscle actin (Fig. 1e). Although a switch-like transition between tightly connected epithelial tissues and dispersed individual mesenchymal cells occurs in embryonic development and wound healing, the presence of these EMT transcription factors and biomarkers does not appear to be required for cancer metastasis in humans [7].

\section{Structure and function of the cytoskeleton}

The cytoskeleton allows mammalian cells to resist deformation and coordinates dynamic force-generation for morphological changes and migration [18]. Recent measurements have yielded new insights into the functional role of various cytoskeletal proteins under extreme mechanical stresses. In general, polymerized cytoskeletal filaments tend to be relatively straight (i.e. rigid relative to thermal fluctuations) and are comparable in size to mammalian cells [35]. As a consequence, these semiflexible polymers can become physically entangled as a gel at relatively low concentrations (compared to more flexible synthetic organic polymers) [36]. Reconstituted networks of cytoskeletal filaments also exhibit counterintuitive strain stiffening, meaning that they strengthen under large deformations [37]. Such strain stiffening has been theoretically explained as an entropic mechanism, whereby straightening out a polymer suppresses thermal fluctuations and effectively increases mechanical resistance to deformation [38]. Alternatively, an enthalpic stretching model is based on preferential alignment of filaments in the direction of deformation, so that mechanical resistance is dominated by filament stretching rather than bending [39].

Three types of cytoskeletal polymers are generally found in mammalian cells: filamentous actin (F-actin), microtubules, as well as intermediate filaments (Fig. 2) [18]. F-actin and microtubules are highly conserved throughout cell types and across animal species; they have also been widely studied in a variety of in vitro and

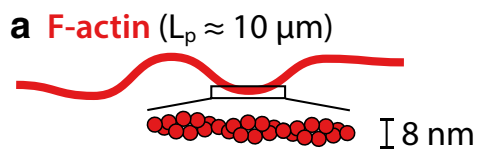

b Intermediate Filament $\left(L_{p}<1 \mu \mathrm{m}\right)$

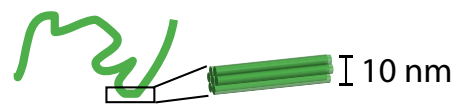

C Microtubule $\left(L_{p}>1 \mathrm{~mm}\right)$

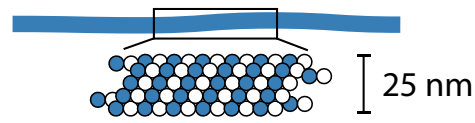

\section{d Cytoskeletal Mechanics}

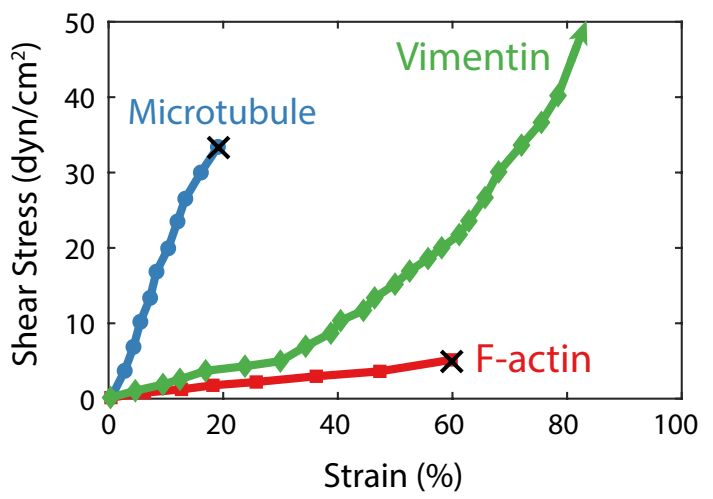

Fig. 2 Cytoskeletal proteins and mechanics. Representative dimensions and structures of F-actin (a), intermediate filaments (b), and microtubules (c), inspired by Pegoraro et al. [35]; " $L_{p}$ " denotes persistence length. $\mathbf{d}$ Mechanical properties of reconstituted microtubule, vimentin intermediate filament, and F-actin networks, based on strain response under applied shear stress. " $X$ " denotes mechanical rupture of network. Replotted from Janmey et al. [40] 
in vivo systems. Both F-actin and microtubules exhibit a structural polarity that results in preferential polymerization at one end, which can generate protrusive forces that drive changes in cell shape. F-actin and microtubule networks are tightly regulated by a host of binding proteins that initiate or terminate monomer addition, disassemble or sever filaments, as well as organize filaments into higher-order crosslinked and oriented architectures [26].

\section{F-actin in cell polarity and directed migration}

F-actin is somewhat flexible as an individual polymer, with a characteristic persistence length $L_{p} \approx 10 \mu \mathrm{m}$ (Fig. 2a, d) [41]. Nevertheless, F-actin can be further organized into mechanically reinforced architectures such as cylindrical bundles or space-filling networks [26]. F-actin polymerization can be spatially coordinated along the cellular periphery; F-actin polymerization in a bundled state drives localized cellular protrusions (i.e. filopodia), while branched network assembly over a broader leading edge advances lamellipodia [3]. F-actin can also be assembled with myosin motor proteins in an antiparallel configuration to form stress fibers, which enable cells to apply contractile tractions to the extracellular matrix [42].

During directed cell migration, these processes act in sequence to translocate the cell body across a 2D surface or 3D matrix [43], regulated by RHO GTPases [44]. In particular, RHOA activation stimulates focal adhesion formation and actomyosin contractility, which can occur in response to TGF- $\beta$ stimulation [45]. Subsequently, Rho-associated kinase (ROCK) signaling can promote actin polymerization via the formin diaphanous 1 (DIA1), along with inhibition of the actin stabilizing factor cofilin via LIM kinase (LIMK) [46], which have been recently shown to be crucial for strong protrusions in $3 \mathrm{D}$ matrix [47].

The transition from apicobasal polarity to front-rear polarity further occurs via crosstalk between RHO GTPases and polarity proteins (e.g. Crumbs, PAR, and Scribble) [48]. Breakdown of adherens junctions can translocate E-cadherin and beta-catenin from the cell surface to the cytoplasm [3], activating p120 catenin to locally repress RHOA activity [49]. Moreover, PAR and Scribble complexes will relocate to the leading edge of the cell, activating RAC1 and CDC42 for actin polymerization and membrane protrusion formation [50]. Local RAC1 activation can stimulate PI3K, which promotes microtubule polymerization that drives positive feedback to further stabilize RAC1 [51]. At the cell surface, EMT downregulates integrin $\alpha_{6} \beta_{4}$ that mediates adhesion to laminins in the basement membrane [52], and upregulates integrin $\alpha_{5} \beta_{1}$ to adhere to fibronectin [53], as well as integrin $\alpha_{1} \beta_{1}$ which binds to collagen I (Fig. 1e) [54,
55]. This process can also include an intermediate step of matrix remodeling via localized proteolysis (e.g. matrix metalloproteinases MMP2, MMP9, [56]) after integrin binding [57], although cells are also capable of "squeezing" forward using a propulsive amoeboid phenotype (which may not require matrix remodeling).

\section{Intermediate filaments and EMT}

Intermediate filaments relevant to EMT include vimentin (a biomarker for mesenchymal phenotype) [34], as well as keratin (a biomarker for epithelial phenotype, also known as cytokeratin) [58]. Intermediate filaments tend to be relatively flexible $\left(L_{p}<1 \mu \mathrm{m}\right)$ [59] and resist tensile forces more effectively than compressive forces (Fig. 2b) [40]. Intermediate filaments assemble laterally, whereby two monomers associate via their central domains to form parallel helical coils around each other [60]. Two dimers associate with each other in an antiparallel arrangement to form a staggered tetramer. The lateral association of multiple tetramers results in the formation of a unitlength filament (ULF). Subsequent longitudinal annealing of ULFs results in filament elongation, which is followed by radial compaction to achieve the final intermediate filament diameter. In contrast to F-actin organization, this assembly mechanism results in a polymer that lacks directional polarity and does not interact specifically with molecular motors. Nevertheless, as a consequence of this winding, rope-like organization, intermediate filaments can withstand large deformations without breaking (Fig. 2d). Indeed, in vitro experiments found that reconstituted networks of both vimentin and keratin networks are predominantly elastic, with a strong nonlinear stiffening behavior [61]. Similar to vimentin networks, keratin networks (e.g. K8/K18, K5/K14) show an elastic behavior under bulk rheology, with a weak frequency dependence [62, 63]. Interestingly, keratin networks have comparable mechanical properties as vimentin networks, with a shear storage modulus $G^{\prime} \sim 1 \mathrm{~Pa}$ at a concentration of $\approx 1 \mathrm{mg} / \mathrm{mL}$. The addition of divalent cations such as $\mathrm{Ca}^{2+}$ and $\mathrm{Mg}^{2+}$ can act as crosslinkers that stiffen vimentin or keratin networks [64], and can also facilitate bundle formation [65]. This is highly relevant to the regulation of cell mechanics since the concentrations of divalent cations in mammalian cells often change drastically in space and time [66]. One caveat of these reconstituted intermediate filament networks is that they are not phosphorylated as they would be in the mammalian cytoskeleton, since they are often prepared by recombinant expression in bacteria (which lacks homologs of these intermediate filament proteins). This lack of phosphorylation is likely to affect intermediate filament assembly, network architecture, and mechanics. Thus, recent efforts have focused 
more directly on probing the mechanics of IF networks in situ in mammalian cells.

Intermediate filaments are thought to protect cells against extreme deformation, and genetic manipulation of vimentin or keratin is often deleterious [34]. It should be noted that keratin is more complex in its biological regulation compared to vimentin. Mutations that impair keratin intermediate filament assembly (e.g. K5, K14) result in mechanically fragile skin that blisters easily, known as epidermolysis bullosa simplex (EBS) [67]. In single keratinocytes, keratin depletion also results in greater deformability and invasion $[68,69]$, but is not sufficient for EMT in cell lines or mouse models [70, 71]. In comparison, genetic knockout of vimentin in mouse models resulted in impaired cell migration and wound healing $[72,73]$. Overall, the functionality of intermediate filaments remains poorly understood, particularly since its dynamics are considerably slower than other cytoskeletal proteins (polymerizing in minutes with network remodeling on the order of hours).

\section{Microtubules and cytoskeletal crosstalk}

Microtubules are the most rigid of cytoskeletal filaments, with a characteristic straightness (i.e. persistence length $L_{p}$ ) that exceeds $1 \mathrm{~mm}$ (Fig. 2c) [41]. Thus, microtubules exhibit nearly straight conformations within a cell and emanate radially outwards from the cell nucleus, analogous to a hub and spoke geometry. Although microtubules are relatively stiff, they can buckle under relatively small strains, which triggers rapid disassembly (Fig. 2d) [74]. This so-called dynamic instability has been proposed as a mechanism to efficiently search intracellular space for chromosomes, facilitating mitotic spindle formation during cell division.

Coordinated activities between cytoskeletal proteins are likely to enhance cell migration. Previous work has focused on individual cells (e.g. fibroblasts) in 2D culture. For instance, nascent focal adhesions driven by actin polymerization may be reinforced by vimentin through the cytoskeletal linker plectin [75]. Similarly, vimentin has been shown to directly interact with the actin-binding protein filamin $\mathrm{A}$, which mediates integrin trafficking and activation [76]. Alternatively, vimentin and microtubules assemble cooperatively via APC, which acts to sustain cell polarity [77]. Furthermore, vimentin disassembly modulates actin-based lamellipodia, which also maintains an asymmetric morphology [78]. Moreover, the focal adhesion scaffold protein Hic-5 has been implicated in the regulation of vimentin networks in fibroblasts [79], as well as cell shape and invasion of breast cancer cells [80].

More recent work with cell monolayers in 2D culture showed that intermediate filaments can also sustain cell-cell contacts and bias cell-matrix adhesions [81]. The crosstalk between cytoskeletal components for 3D migration is less well understood, although all three cytoskeletal proteins have been shown to play a role in invadopodia-based protrusions through the basement membrane [82].

\section{Scattering and leading: new insights from old assays}

Cell scattering assays reveal how adherent epithelial clusters disperse into migratory individuals after exogenous treatment with soluble factors on planar 2D substrates, analogous to an EMT (Fig. 3a). For example, MadinDarby canine kidney (MDCK) epithelial cells typically form isolated multicellular clusters with strong E-cadherin junctions, which disassemble after treatment with hepatocyte growth factor (HGF, "scatter factor") [83, 84]. de Rooij et al. [85] subsequently showed that HGF treatment increases actomyosin contractility via integrinmediated substrate adhesion, independent of E-cadherin expression. In order to directly visualize cell-generated forces, Maruthamuthu et al. plated MDCK cells on compliant polyacrylamide hydrogel substrates labeled with fluorescent tracer particles [86]. These MDCK clusters initially exhibited strong tractions around the periphery, as well as strong intercellular adhesions through E-cadherin (Fig. 3b). Upon HGF stimulation, some MDCK cells extended protrusions in the direction perpendicular to the cell-cell interface, resulting in a sudden rupture. In comparison, other MDCK cells extended protrusions in a direction parallel to the cell-cell interface, resulting in a gradual decrease in cell-cell adhesion before detachment. These results confirm that HGF does not directly weaken cell-cell junctions (e.g. by downregulation of E-cadherin), but rather mediates the mechanical crosstalk with the actin cytoskeleton and focal adhesions. Loerke et al. subsequently implemented image-based phenotypic screening of scattering MDCK cells, which identified a number of targeted inhibitors that acted on cell-cell adhesion, migration, or both [87].

So-called "wound healing" assays characterize how sheet-like monolayers migrate collectively to occupy empty regions of planar 2D substrates [9]. Gilles et al. [88] investigated vimentin expression in confluent mammary epithelial cells (MCF-10A) after applying controlled damage in a circular region using a drop of sodium hydroxide. Initially, vimentin expression was minimal in the confluent epithelial monolayer (Fig. 3c). After $24 \mathrm{~h}$, vimentin expression occurred in a localized region near the migration front, associated with "leader cells" undergoing a (partial) EMT (Fig. 3c). By 8 days, vimentin expression was again minimal everywhere once cells had reestablished a confluent monolayer. Moreover, 
a Cell Scatter Assay (HGF Treatment)

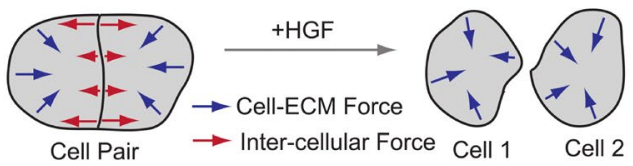

b Traction Force Microscopy
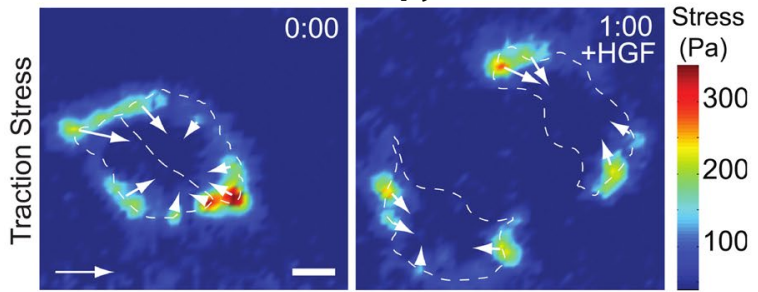

\section{c "Wound-Healing" Assay}
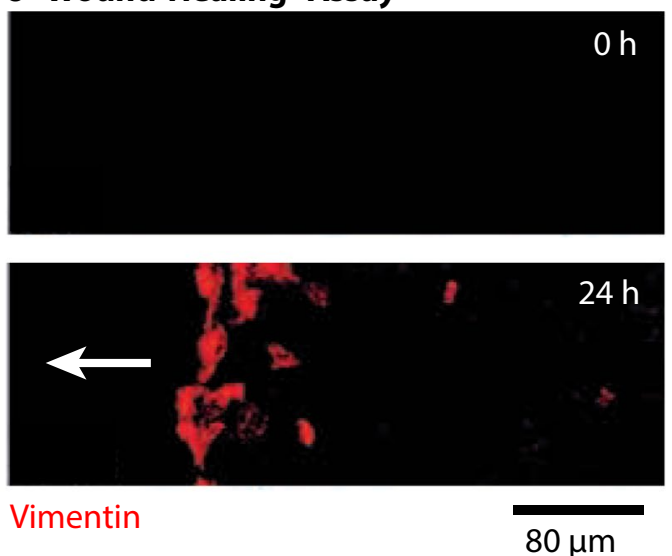

$80 \mu \mathrm{m}$

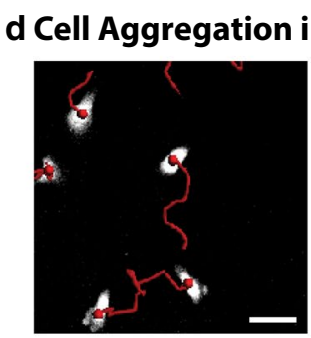

$6 \mathrm{~h}$

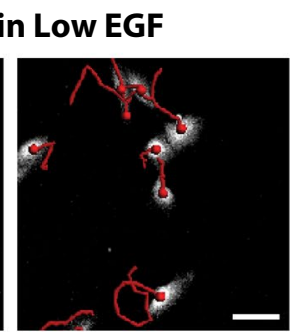

$12 \mathrm{~h}$

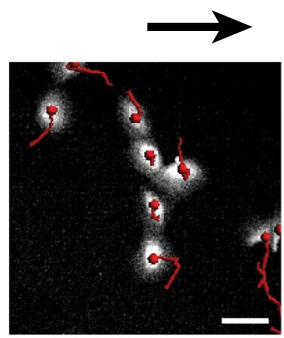

$18 \mathrm{~h}$

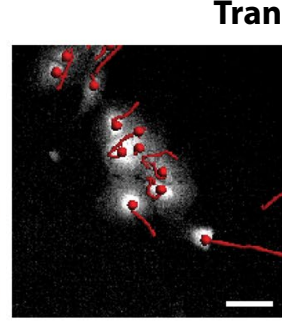

$24 \mathrm{~h}$
Transient Leader Cells

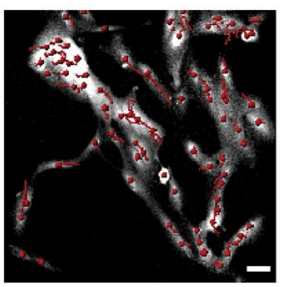

$48 \mathrm{~h}$

Fig. 3 Scattering, wound-healing, and aggregation assays. a Scattering assays visualize how multicellular epithelial (MDCK) clusters disperse into migratory individuals in response to exogeneous biochemical stimulation (e.g. HGF). b Traction force microscopy reveals cell-generated forces on deformable substrates, which are localized at the cluster and cell periphery. Reproduced from [86] with permission. c Wound healing assays visualize the collective migration of sheet-like monolayers into unoccupied regions. Mammary epithelial (MCF-10A) cells at the migration front (wound edge) gain vimentin expression (vimentin immunolabeling, red), analogous to an EMT. Reproduced from Gilles et al. [88] with permission. d Mammary epithelial cells cultured with reduced levels of epidermal growth factor initially aggregate into multicellular clusters, analogous to a reverse mesenchymal-to-epithelial transition. GFP cytoplasm (white) with individual cell tracks (5h, red). Subsequently, leader cells transiently guide migration to link clusters together into spanning networks. Reproduced from [89] with permission

knockdown of vimentin expression impeded the migration of these leader cells and front closure. Similarly, vimentin expression and migration were attenuated for wounded cultures deprived of epidermal growth factor (EGF). Subsequently, Riahi et al. spatially profiled gene expression of leader cells in a different mammary epithelial cell line (MCF-7), revealing EMT occurred through Notch1-Dll4 signaling [90]. Subsequent research by Reffay et al. [91] demonstrated that these leader cells mechanically coordinate followers through actomyosin contractility acting through cell-cell junctions.

Leggett et al. [89] showed that mammary epithelial cells in reduced EGF exhibit multicellular aggregation into clusters (analogous to a reverse MET), followed by leader cell formation. Since nontransformed mammary epithelial cells (MCF-10A) are growth factor dependent, their proliferation and migration was slowed when cultured at low exogenous EGF concentrations. As a consequence, initially dispersed individuals migrated randomly, but adhered tightly together when encountering another. This behavior persisted for cells with induced expression of Snail, which would otherwise undergo a complete EMT and remain individual when cultured in growth media containing saturating levels of EGF. Over $24 \mathrm{~h}$, these individuals transitioned to multicellular clusters that adopted branching morphologies, since they did not rearrange into more compact morphologies (Fig. 3d). Subsequently, leader cells emerged at the periphery of these branches with transient migration outward, which eventually came into contact with adjacent clusters. Finally, these initially isolated clusters merged together as sparse, space-filling networks. This self-organizing process has remarkable quantitative analogies to the physics of aggregating, non-living colloidal particles, which undergo random walks with irreversible adhesion, and organize into space-filling, fractal-like structures [92], analogous to branching networks of epithelial or endothelial cells. 


\section{Squeezed and stretched: intermediate filaments and EMT}

Mendez et al. manipulated vimentin expression within a mammary epithelial cell line (MCF-7), resulting in dramatic alterations of cell morphology and EMT [93]. Luminal-like MCF-7 cells express only keratins and adopt a rounded morphology in 2D culture (Fig. 4a), consistent with an epithelial phenotype. Remarkably, microinjection of recombinant vimentin into these cells was sufficient to cause cellular elongation into a spindle-like morphology (Fig. 4b, c). Moreover, forced transfection of vimentin caused MCF-7 to weaken cell-cell junctions, dispersing as individuals with increased motility. Conversely, RNA silencing of vimentin in mesenchymal breast cancer cell lines (MDA-MB-435) resulted in more compact morphologies consistent with epithelial cells. Analogous results were observed using nocodazole drug treatment to depolymerize microtubules, which in turn reorganized vimentin architecture. Thus, transitions between epithelial and mesenchymal states can occur directly through cytoskeletal organization without manipulation of EMT transcription factors and E-cadherin.
Guo et al. recently used optical tweezers to directly probe vimentin mechanics within live mouse embryonic fibroblasts (mEFs) [95]. Subsequently, $\mathrm{Hu}$ et al. found that vimentin positive wild type mEFs exhibited significantly higher strength, stretchability, and toughness relative to vimentin knockouts [94]. Moreover, the presence of vimentin networks decreases the effective cytoskeletal mesh size and thus increases both viscoelastic and poroelastic relaxation times of the cytoskeleton [94, 96]. Indeed, vimentin dominated the mechanical response of mEFs, especially at large deformations ( $>50 \%$ strain), while cell mechanics at small deformations was mainly attributed to other cytoskeletal components. This is consistent with macroscopic rheology measurements of reconstituted cytoskeletal networks, where vimentin was much more extensible before failure relative to F-actin or microtubules (Fig. 2d) [40]. These results suggest that vimentin increases the deformability of the cytoskeleton (Fig. 4d, e), and is thus more robust against large deformations. Indeed, these wild type mEFs retained high viability (>90\%) after being subjected to uniaxial stretch (up

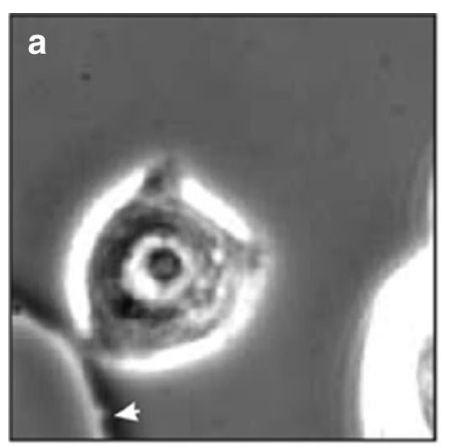

d

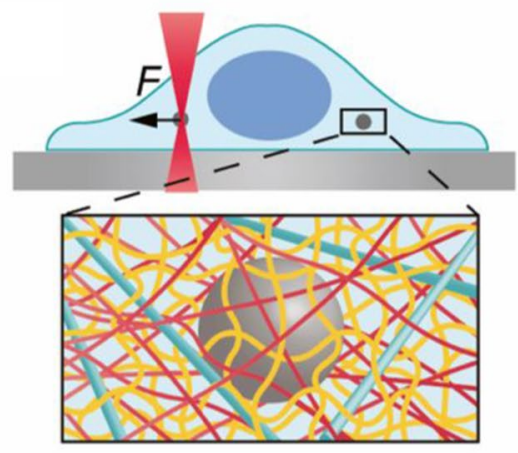

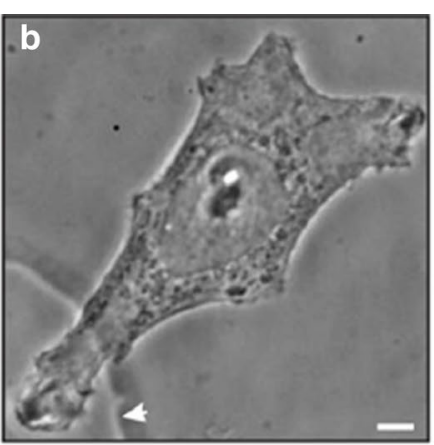
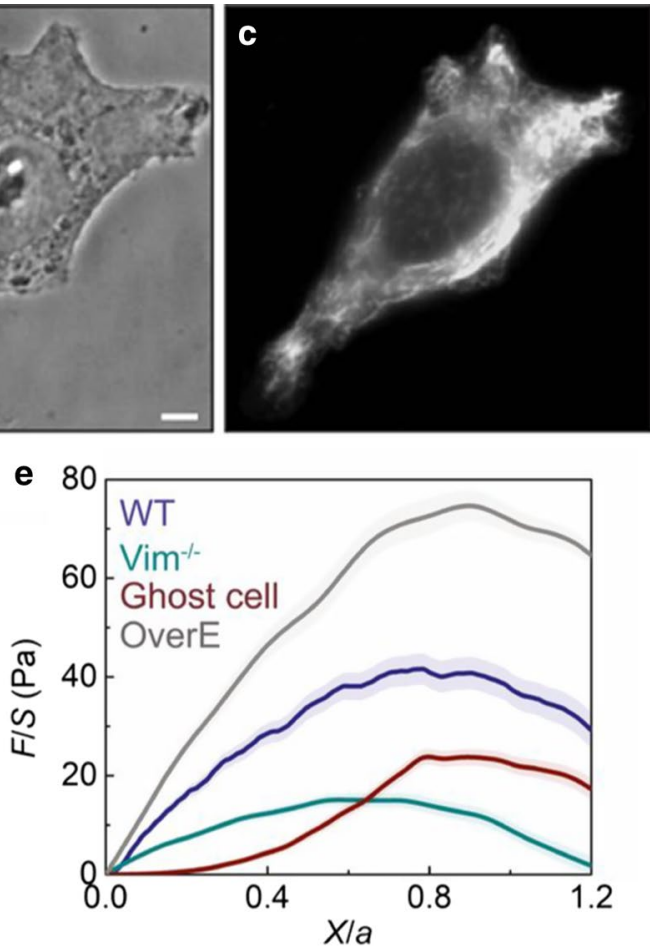

Fig. 4 Cell morphology and mechanics are vimentin dependent. a Epithelial breast cancer cells (MCF-7) that only express keratin are initially compact and rounded. b After microinjection of recombinant vimentin, cells adopt an elongated, mesenchymal-like morphology, with c immunofluorescence staining (vimentin). Reproduced from [93]. d Optical tweezer measurements manipulate embedded tracer particle to probe local cytoskeletal mechanics. e Increasing vimentin expression in mouse embryonic fibroblasts increases mechanical deformability before yielding. Abbreviations denote vimentin knockout (Vim -/-), decellularized vimentin ("ghost cell") with all other cellular components removed, wildtype (WT), and vimentin overexpression (OverE). Reproduced from [94] 
to $300 \%$ strain), while vimentin knockout fibroblasts exhibited poor viability under comparable strains.

Microfabricated structures have been used to further investigate cell migration in confined spaces [15]. Wong et al. [97] prepared micropillar arrays with a fibronectin-coated silicone elastomer (poly-dimethylsiloxane), with spacing and height of $10 \mu \mathrm{m}$ (Fig. 5a). Mammary epithelial cells (MCF-10A) with induced Snail expression migrated through these micropillars as individual mesenchymal cells (with vimentin expression), followed by a collective epithelial front (with E-cadherin expression) (Fig. 5b). This narrow $10 \mu \mathrm{m}$ pillar spacing was crucial by limiting cell-cell adhesions, permitting individual mesenchymal cells to detach and disseminate. In comparison, slightly wider spacings resulted in single or multi-file migrations, since epithelial cells had enough room to reorganize and advance without fully breaking cell-cell adhesions. This work was combined with automated single cell tracking to automatically classify subpopulations that exhibited collective or individual migration, which correlated with drug response to targeted inhibitors.

Patteson et al. [98] investigated how vimentin affects confined cell migration across a Transwell membrane with 3-8 $\mu \mathrm{m}$ diameter pores, as well as microchannels [99] (Fig. 5c). Vimentin positive wild type mouse embryonic fibroblasts exhibited impaired migration through confined spaces relative to vimentin knockout fibroblasts. However, vimentin knockout fibroblasts suffered increased nuclear damage, with blebbing and DNA double-strand breaks (Fig. 5d). Thus, vimentin mechanically cushions the cell nucleus against compression and nuclear rupture through the presence of a stiff perinuclear shell. This work complements recent results on lamin intermediate filament expression, which also serves to protect the cell nucleus in confined spaces $[100,101]$. Overall, these results indicate that vimentin plays an important role in mesenchymal cells both to

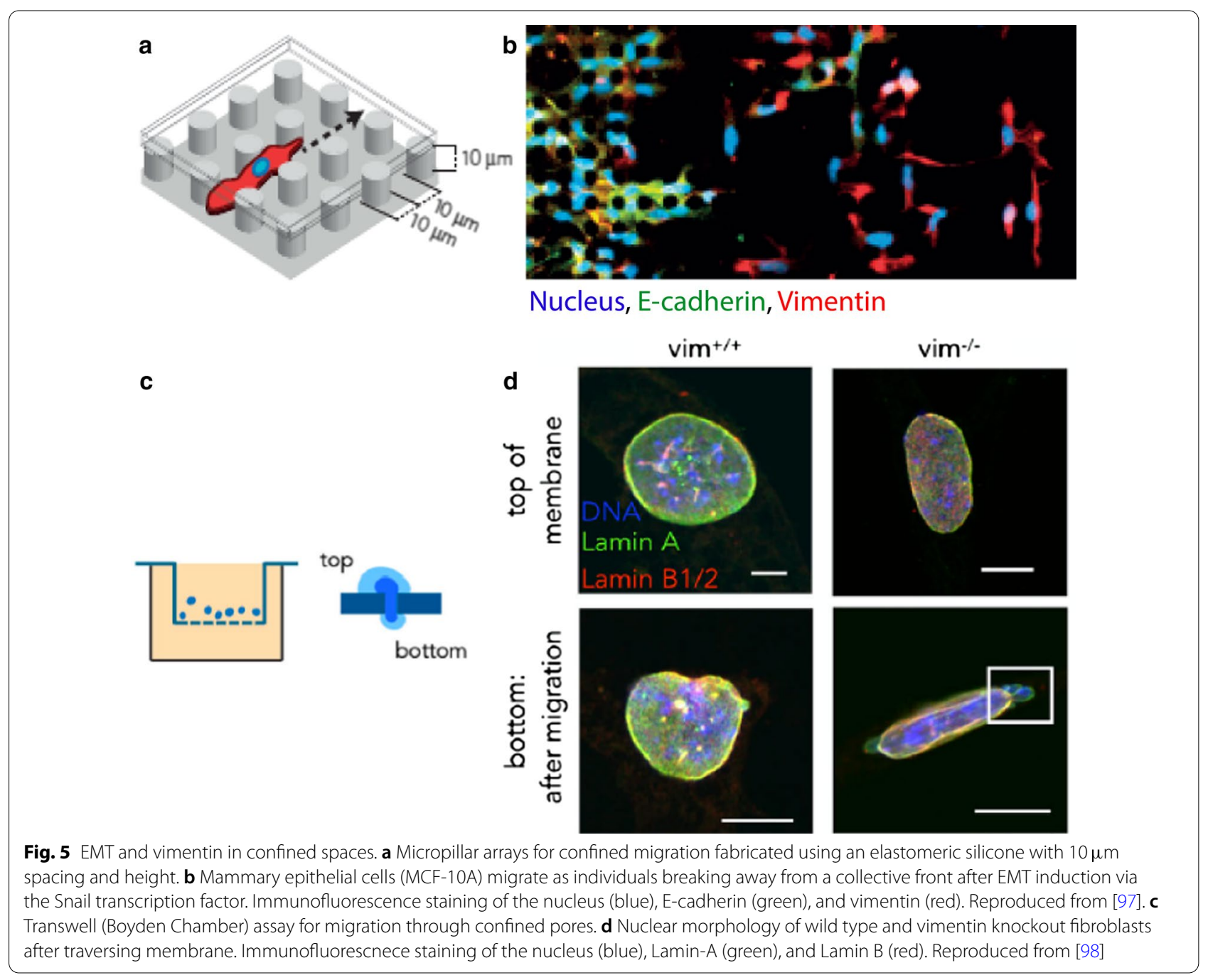


coordinate cell migration and permit nuclei and cells to undergo large deformations.

\section{On the tracks: EMT and micro/nano topographies}

Classical 2D monolayer culture presents a uniform and flat surface topography that does not spatially bias cell shape or adhesion. In comparison, the extracellular matrix in vivo can be highly fibrillar, with collagen fibers ranging in diameter from 20 to $200 \mathrm{~nm}$ [102]. Historically, synthetic nanofibers have been prepared by electrospinning to model such topographies, which extrude viscous polymeric solution from a nozzle under extremely high electric fields and permits limited control over fiber size and organization [103]. Epithelial cells cultured on these fibrillar topographies tend to exhibit elongated morphology, directed migration, and some EMT-associated gene expression [104-107]. Moreover, grooved topographies can also be prepared by controlled "wrinkling" of a stiff coating on a softer substrate [108], which can be reversibly actuated $[109,110]$.

Instead, Texeira et al. [111] patterned submicron grooves with highly controlled geometries by etching silicon wafers, utilizing standard photolithography techniques established for integrated circuit fabrication. Primary human corneal epithelial cells cultured on planar silicon remained rounded and compact (Fig. 6a). However, epithelial cells cultured on nanogrooves exhibited spatially restricted adhesions of filopodia and lamellipodia along the ridge walls (Fig. 6b). As a consequence, these epithelial cells aligned and elongated their cell body along the ridge direction, analogous to an EMT driven by "contact guidance" (Fig. 6c). Subsequently, Ray et al. systematically investigated how different cancer cell lines of varying mesenchymal state were affected by grooved topographies [112]. Interestingly, mesenchymal cells more strongly responded to topography, but isolated epithelial cells without contacts also responded to topography, although in a less pronounced manner. Moreover, epithelial clusters responded to topography only when leader cells extending protrusions were re-directed by nearby topographical boundaries. Thus, cellular transduction of surface topography is mediated by crosstalk with cell-cell adhesions, and is likely to be highly responsive to specific microenvironmental conditions.

Park et al. [113] further investigated how nanotopographical cues affect collective cell migration and EMT. Kidney epithelial cells (MDCK) were cultured as multicellular sheets on grooved substrates. Consistent with previous work, collagen-coated ridges alone are sufficient to induce an EMT phenotype at the advancing margins, with migration velocities similar to TGF- $\beta$ treated cells forced into EMT on flat substrates. The degree of EMT was shown to exist as a gradient in the migrating cell

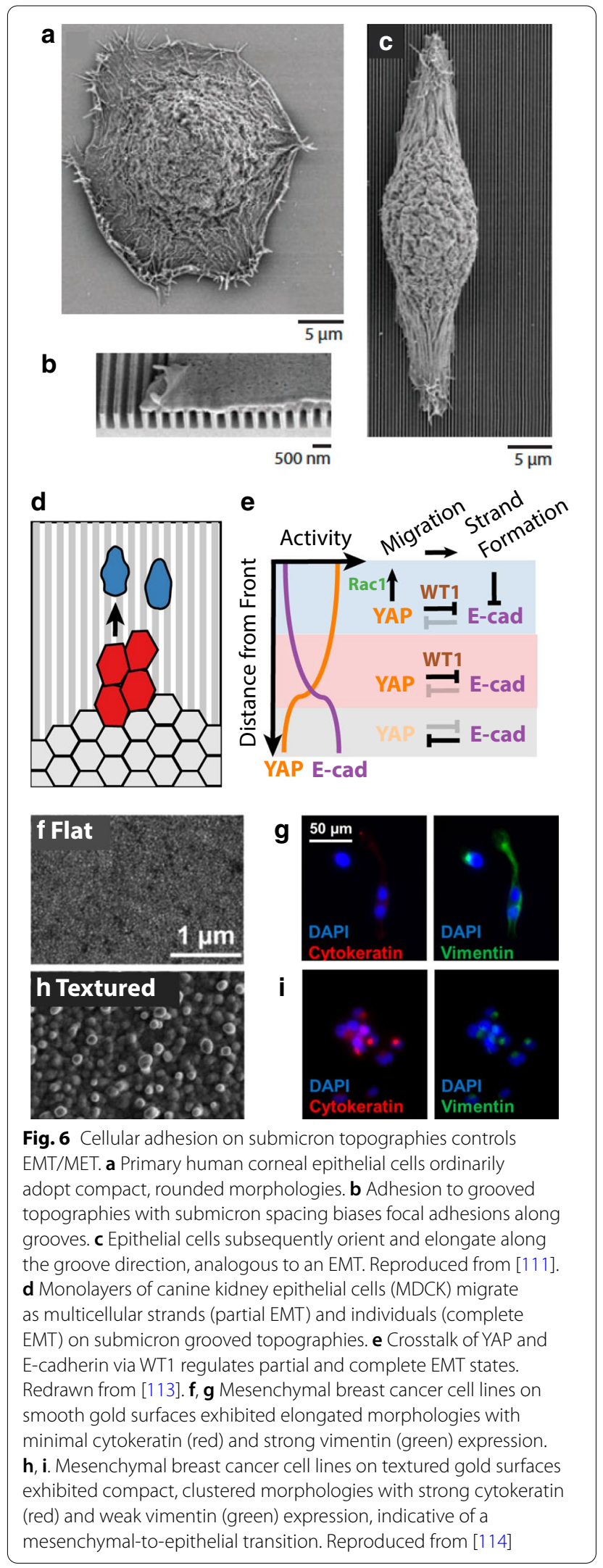


sheet, in which partial to complete EMT is observed in leader cells with few cell-cell contacts, and suppression of EMT is observed in tightly packed cells in the center of the sheet with many neighbors (Fig. 6d). The authors found that the activity of YAP mirrored the distribution of EMT states: YAP was active and localized to the nucleus in leader cells, while it was diffuse in the cytoplasm for cells in the center. Further, authors identified two cross-regulatory networks of YAP that control YAP's sensitivity to topography (Fig. 6e). First the Wilms tumor protein (WT1), associated with regulating MET and kidney development, was found to be transcriptionally regulated by forming a complex with YAP, which in turn suppressed E-Cadherin, promoting the strongest EMT phenotype in leader cells with few cell-cell contacts. Second, YAP activity upregulated Rac-1 and thus enhanced migration speed in leader cells. These results solidify the notion that pure mechanical cues regulate gene expression: cells with enhanced EMT activity due to micrograte topography exhibit reduced migration capacity when YAP is knocked down. However, when ROCK is also knocked down, Rac-1 mediated migration activity is rescued only in cells on micrograted surfaces, but not flat surfaces. Indeed, the activity of these molecular regulators follows the observed gradient in YAP activity and EMT phenotype.

Wang et al. [114] patterned hierarchical textures in gold using electrochemical deposition techniques, inspired by the fractal-like topography of bone tissue (Fig. 6f, h). Interestingly, the authors found that submicron surface texturing caused mesenchymal breast and prostate cancer cell lines to revert to an epithelial phenotype, representing a reverse mesenchymal-to-epithelial transition (MET). In response to nanotopography and limited cellsubstrate adhesions, cells exhibited rounded morphology, reduced proliferation observed via Ki-67, as well as increased junction formation indicated by increases in ICAM1, E-Cadherin, and keratin expression, while cells on bare gold substrates maintained a mesenchymal phenotype (Fig. 6g, i). Further, cells interacting with nanostructures displayed down-regulated RhoA and Cdc42, whereas Rac1 maintained high levels of expression compared to cells residing on flat gold substrates (Fig. 6h, i). A global decrease of mesenchymal markers was observed, including N-Cadherin, vimentin, ZEB1 and ZEB2. These effects corresponded to functional differences in migration capacity, in which MET'd cells displayed a decreased wound-healing response and diminished migration in Transwell chamber assays. Cells were then re-cultured on flat tissue culture plastic (TCP) for 7 days following the initial 7-day incubation on nanostructures. These re-cultured cells maintained their rounded morphology and expression of junction proteins, but displayed more active proliferation, indicating growth arrest was transient. Finally, the authors showed that the nanostructuremediated MET process is transduced by downregulating glycogen synthase kinase-3 (GSK-3) phosphorylation, which decreased the expression of Snail. Overall, these findings demonstrate that diminished cell-matrix adhesions via nanotopographical cues may be compensated for by enhanced cell-cell adhesions, which would promote a clustered epithelial cell state.

\section{Enter the matrix: EMT in 3D}

Epithelial cells embedded within a compliant tri-dimensional (3D) matrix recapitulate tissue architecture and invasive behaviors observed in vivo. In particular, single cells cultured in reconstituted basement membrane (i.e. Matrigel) or collagen I will organize into multicellular clusters with differentiated architectures, strong cell-cell junctions, as well as hollow lumens that mimic ducts or glands $[13,115]$. Notably, an increase in matrix stiffness is sufficient to drive the disorganization and local dissemination of multicellular clusters via integrin-mediated signaling $[116,117]$. Indeed, cancer cells exhibit cytoskeletal polarization and directional migration in response to diverse "-taxis" phenomena. Guiding cues driving these behaviors include soluble signals (i.e. chemotaxis) [118], bound chemo-attractants/repellents (i.e. haptotaxis), stiffness gradients (i.e. durotaxis) [119], local topography or ECM density (i.e. topotaxis) [120], interstitial flow (i.e. rheotaxis) [121, 122], and applied electrical fields (i.e. electrotaxis) [123]. Reconstituted biomaterials have revealed new insights into these processes, as well as the importance of matrix remodeling. In particular, matrix metalloproteinase (MMP) activity is crucial for multicellular (collective) invasion to occur through progressively widening pores [124]. Indeed, 3D traction force microscopy has revealed strong front/back tractions for individual mesenchymal cells, particularly in fibrillar matrix [125-127]. However, MMP activity may be dispensable for individual migration, since cells can utilize a propulsive "amoeboid" mode to squeeze through the matrix, ultimately limited by nuclear deformability and matrix pore size [128].

Transitions from multicellular clusters to collective or individual invasion via EMT-associated signaling can occur in response to both soluble and matrix cues. Notably, Hay's initial demonstration of EMT was induced solely by culture of corneal epithelial cells in fibrillar collagen I matrix [4], which has been corroborated by Reinhart-King's group using mammary epithelial cells (MCF-10A) [129]. Jing Yang's group has shown that stiff substrates (with an overlay of Matrigel) can activate TWIST in mammary epithelial cells (MCF-10A), resulting in enhanced dissemination [130,131]. Friedl's group 
(See figure on next page.)

Fig. 7 Collective invasion and EMT in 3D matrix. a Multicellular clusters of mammary epithelial cells (MCF-10A) cultured in a alginate-Matrigel mixture first form spherical acini over 5 days, but subsequently disorganize and disseminate over 10 days. Remarkably, nuclear and cellular volume increase at the periphery, corresponding to softer intracellular stiffness (right). Reproduced from [142]. b Multicellular clusters also exert spatially non-uniform patterns of protrusive and contractile tractions for epithelial, transitory (EMT), and mesenchymal states induced via Snail. Reproduced from [143]. c Multicellular clusters respond to dynamically stiffened substrates via dissemination and EMT activation via Twist, TGF- $\beta$, and YAP signaling. Reproduced from [144]

has shown that hypoxic conditions can also induce HIF1 and downstream EMT signaling, which unexpectedly results in amoeboid rather than mesenchymal migration in murine breast cancer cells (4T1) [132]. EMT can also be induced by exogenous treatment with growth factors (e.g. EGF, HGF, TGF- $\beta$ ) in various epithelial cell lines, resulting in collective invasion and branching morphogenesis [133-137]. Nevertheless, EMT induction is not accompanied by invasion in synthetic $3 \mathrm{D}$ matrices that resist MMP degradation [138, 139]. It should be noted that EMT induction in 3D matrix also depends sensitively on cell-cell junctions. Indeed, Snail induction is impeded in multicellular clusters of mouse mammary epithelial cells with established apicobasal polarity [140]. Moreover, Ewald's group showed that Twist induction in primary mouse mammary epithelial organoids results in collective invasion that retains E-cadherin expression [141]. Thus, elucidating EMT in 3D matrix requires careful consideration of tissue architecture and microenvironmental cues.

Han et al. [142] investigated the spatial patterns of cell size and stiffness in an invasive multicellular cluster, or cancer organoid, embedded within a composite Matrigelalginate hydrogel. This composite matrix was engineered to mimic the mechanical properties of breast carcinoma in vivo (shear modulus $\sim 300 \mathrm{~Pa}$, comparable to tumor $\mathrm{ECM}$ ), resulting in the disorganization and dissemination of mammary epithelial cells (MCF-10A) from 5 to 10 days in culture (Fig. 7a). These clusters exhibited considerable spatial heterogeneity in cell size and volume. In particular, cells in the central core remained compact with increased stiffness, while cells at the periphery exhibited increased nuclear volume with decreased cell stiffness (Fig. 7a). Indeed, cells used gap junctions to dynamically manipulate their size by regulating fluid and ion transport. Pharmacological treatments to perturb cell size or stiffness impeded collective invasion at the periphery, but had limited effect on cell proliferation. Moreover, tumor biopsies from breast cancer patients exhibited a similar pattern of larger nuclear sizes at the invasion front, suggesting that differences in cell volume may be important for invasion in vivo. Nevertheless, it should be noted that nuclear and cell morphology are highly dysregulated during tumor progression, which may confound some of these trends.
Leggett et al. [143, 145] investigated the spatial patterns of 3D matrix deformations of multicellular clusters (MCF-10A) at varying stages of inducible Snail expression within a composite silk fibroin-collagen I hydrogel. Epithelial clusters (with no Snail induction) exhibited a spherical morphology and applied both protrusive and contractile tractions to the surrounding matrix (Fig. 7b, i). "Transitory" clusters with Snail induction after embedding extended invasive protrusions and spatially distributed contractile tractions (Fig. 7b,ii). Finally, mesenchymal clusters with Snail induction before embedding were highly elongated with localized contractile tractions in a few locations (Fig. 7b,iii). These spatially nonuniform protrusive and contractile tractions were used to classify clusters into three distinct mechanophenotypes that exhibited $70-75 \%$ agreement with the experimental treatment condition, which is plausible given the intrinsic heterogeneity of these cells. These mechanophenotypes could be perturbed using pharmacological treatment against cytoskeletal or EMT associated pathways. For example, sublethal treatment with the microtubule stabilizing agent Taxol (Paclitaxel) shifted towards more mesenchymal states, so that initially epithelial clusters appeared more transitory, etc. In comparison, treatment with the epidermal growth factor receptor (EGFR) inhibitor Gefitinib had minimal effect on initially epithelial or mesenchymal clusters, but caused the initially transitory clusters to exhibit epithelial or mesenchymal mechanophenotypes. It should be noted that this technology was implemented on a 96 well plate, enabling higher throughput measurements of cell-matrix interactions across different drug treatment conditions.

Ondeck et al. investigated multicellular dissemination and EMT using biomaterials with time-varying stiffness [144]. Their system utilized an underlying substrate consisting of methacrylated hyaluronic acid (HA), which was partially crosslinked using ultraviolet light to be "soft," (100 Pa) and could subsequently be "stiffened" (3000 Pa) through additional ultraviolet exposure (Fig. 7c). These substrates were coated with collagen I, and further overlaid with mammary epithelial cells (MCF-10A) and Matrigel. Typically, single cells formed compact acini on soft substrates, but disseminated as elongated mesenchymal cells on stiffened substrates. Interestingly, the extent of dissemination depended on the duration of culture on 
a Nuclear Size and Cell Stiffness Vary Across Clusters
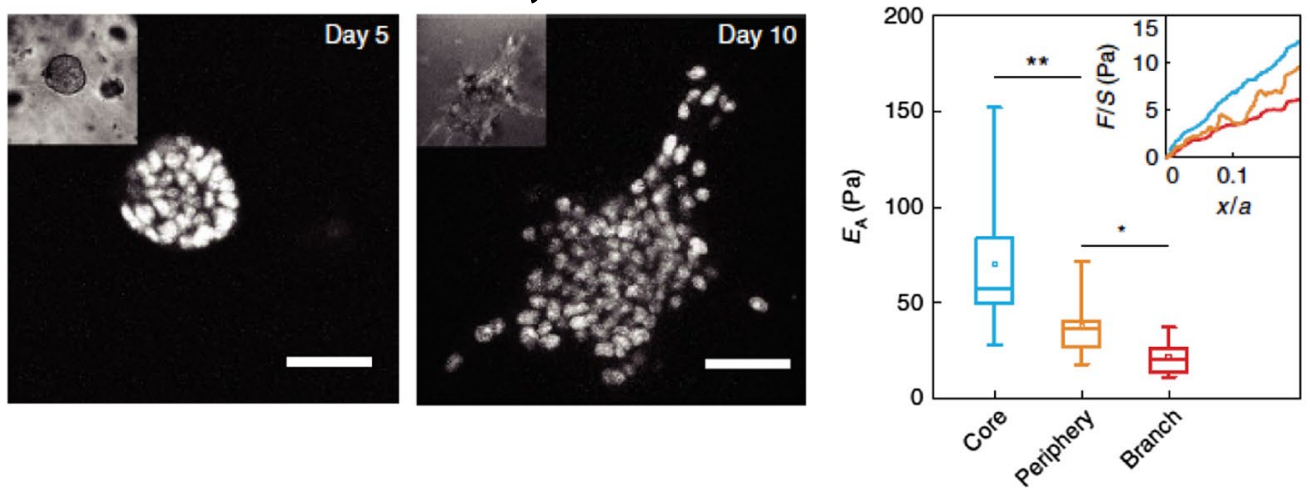

b Spatial Patterns of 3D Matrix Deformation
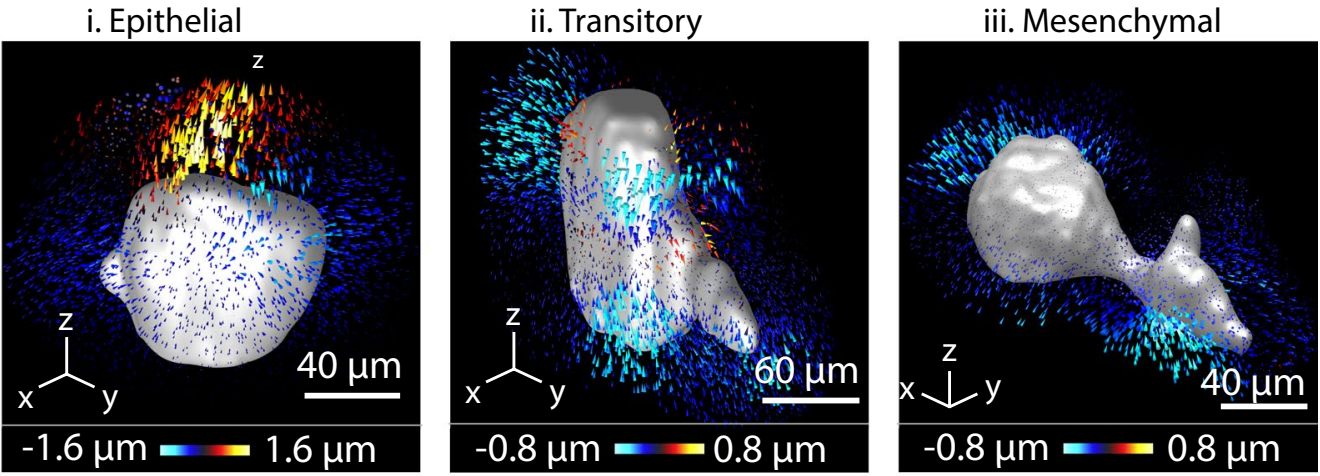

c EMT and Dissemination with Time-Varying Stiffness

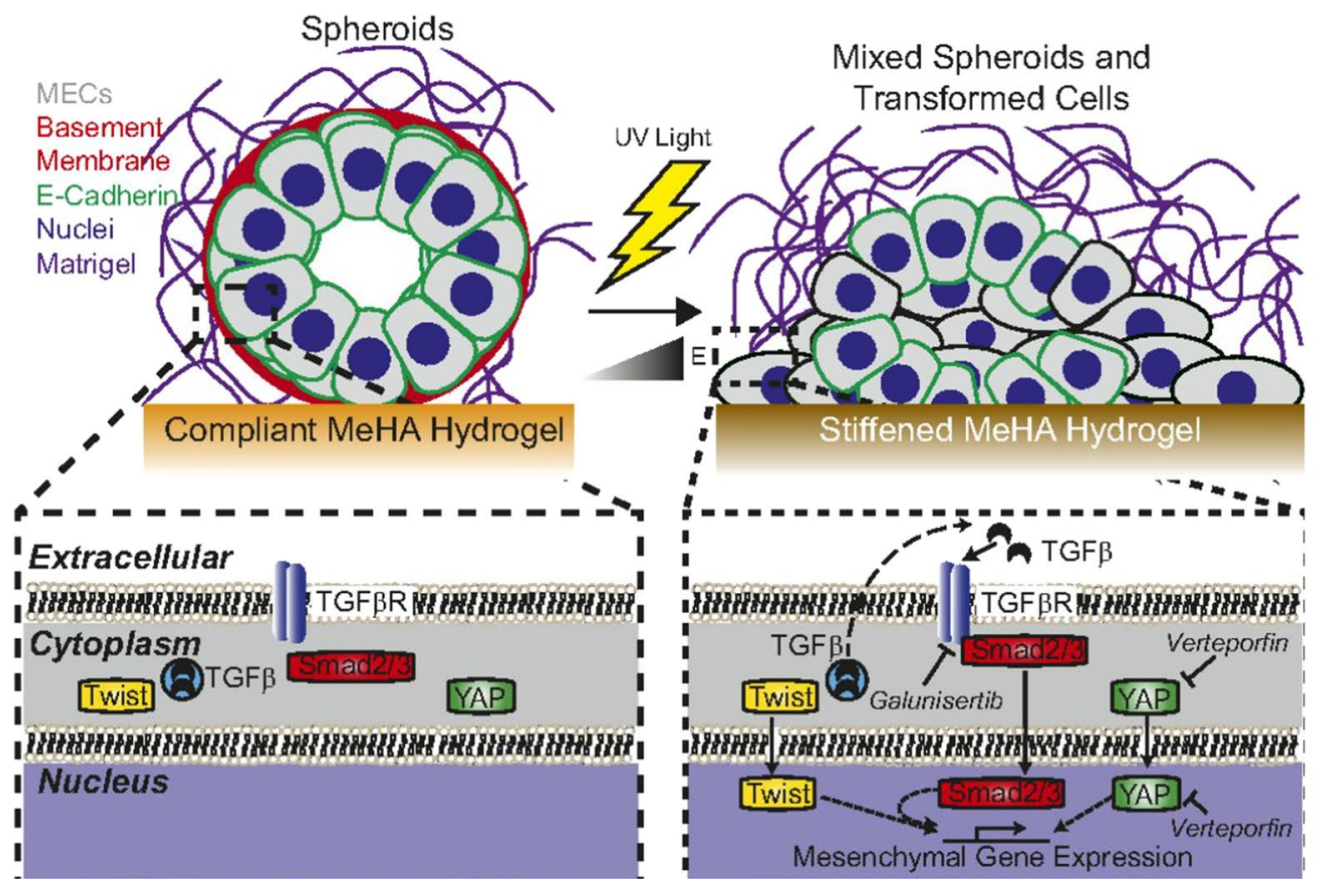


soft substrates. For example, cells cultured for shorter durations on soft substrates exhibited complete dissemination after stiffening. However, some cells cultured for extended durations (10 days) on soft substrates remained as compact acini after stiffening. This heterogeneous response was recapitulated when cells were sorted as individuals or acini, then re-cultured on a new biomaterial, suggesting a lack of mechanical "memory." Immunofluorescence staining suggested that these heterogeneous responses were driven by a combination of paracrine signaling through TGF- $\beta /$ SMAD, as well as YAP localization. The combined inhibition of these two pathways through Galunisertib and Verteporfin impeded migration and rescued epithelial acini even on stiffened substrates. It should be noted that this overlay geometry does not fully confine cells relative to complete embedding in 3D matrix, which has been reported to limit YAP activation [146]. Nevertheless, the use of time-varying biomaterials represents an elegant approach to investigate phenotypic plasticity and EMT.

Finally, Ranamukhaarachchi et al. showed that mesenchymal breast cancer cell lines could revert to epithelial biomarker expression within a collagen I matrix with compacted fibrils [147]. Briefly, collagen I networks were polymerized in the presence of an inert macromolecular crowding agent (polyethylene glycol) at varying concentrations. The crowding agent decreased collagen I fiber length and degradability, while leaving porosity and stiffness roughly comparable to the untreated controls. As a consequence, adenocarcinoma cells (MDA-MB-231) formed connected multicellular tubule architectures in collagen I networks formed with the crowding agent. Indeed, at very high concentrations of crowding agent, these cells formed epithelial acini with hollow lumens and cell-cell junctions (e.g. PECAM1, ICAM1). This is particularly noteworthy since MDA-MB-231 is a highly mesenchymal cell type with minimal E-cadherin junctions, which is difficult to revert to an epithelial phenotype. This result has analogies with the MET observed by Wang et al. [114] on nanostructured topographies with reduced cell-substrate interactions, illustrating the role of matrix architecture on epithelial plasticity.

\section{Discussion}

\section{Precision measurement and engineering of the local mechanical microenvironment}

EMT is associated with the dynamic acquisition of an elongated, migratory phenotype, which is mediated by a redistribution of cell-matrix adhesions [22]. In order to resolve these cell state transitions, there is an increased need to map molecular and subcellular changes within a heterogeneous population over space and time [148]. Bioengineering approaches allow direct visualization of how cells apply forces to a compliant biomaterial, both on planar 2D substrates [86] as well as tri-dimensional 3D matrix [143], which we summarize in Table 1. In 3D, epithelial cells are initially compact and round with uniformly distributed tractions around the periphery. Activation of EMT pathways drives protrusion formation around the cell periphery, as well as localizing tractions at the front and back, ultimately resulting in a spindlelike morphology. We envision that the sensitivity of these mechanical measurements could be further improved using emerging imaging modalities to resolve tracer particles at high density (e.g. super-resolution microscopy) [149], or directly resolve fibrillar matrix proteins (e.g. second harmonic generation) [150]. Moreover, an improved understanding of the mechanical response (i.e. constitutive equations) of extracellular matrix is needed, since these fibrous networks also exhibit strain-stiffening [36] and can be extensively remodeled by cells [5].

Biomimetic materials can also be engineered to shape cell-matrix adhesions in order to perturb EMT. Individual cells cultured on topographical patterns such as submicron grooves will align and elongate [111, 112], while leader cells can emerge from the collective migration front of multicellular sheets [113]. Similarly, clusters can disorganize and disseminate in stiffer and more fibrillar 3D matrix $[116,117]$, which mimics the desmoplastic stroma in malignant tumors [5]. Conversely, impeded cell-matrix adhesions on fractal-like topographies [114] or degradation-resistant collagen I [147] can force mesenchymal cells to revert to an epithelial state. Overall, Hippo/YAP signaling appears to play an important role in transducing mechanical cues towards EMT (in conjunction with other pathways) [29], although this may be celltype dependent. An important approach for elucidating time-dependent phenotypic plasticity is to design new biomaterials whose properties can be dynamically tuned by external stimuli [144]. Photopatterning of 3D biomaterial topography and surface chemistry with improved spatial resolution could further shape cell behavior [151], which can be combined with the higher resolution measurement techniques described previously. There is also great interest in decellularized matrix prepared by removing living cells from animal or human tissue, which preserves much of the biochemical and structural complexity of ECM in vivo (see review in [152]). Decellularization techniques have also been applied to ECM deposited by cancer-associated fibroblasts, which can significantly impact cancer cell invasion, proliferation, and gene expression $[153,154]$.

Cell-cell adhesions (e.g. E-cadherin) mediate transitions between anchored tissues, collectively migrating groups, and individual mesenchymal phenotypes [3]. Experiments on planar 2D substrates have shown that 


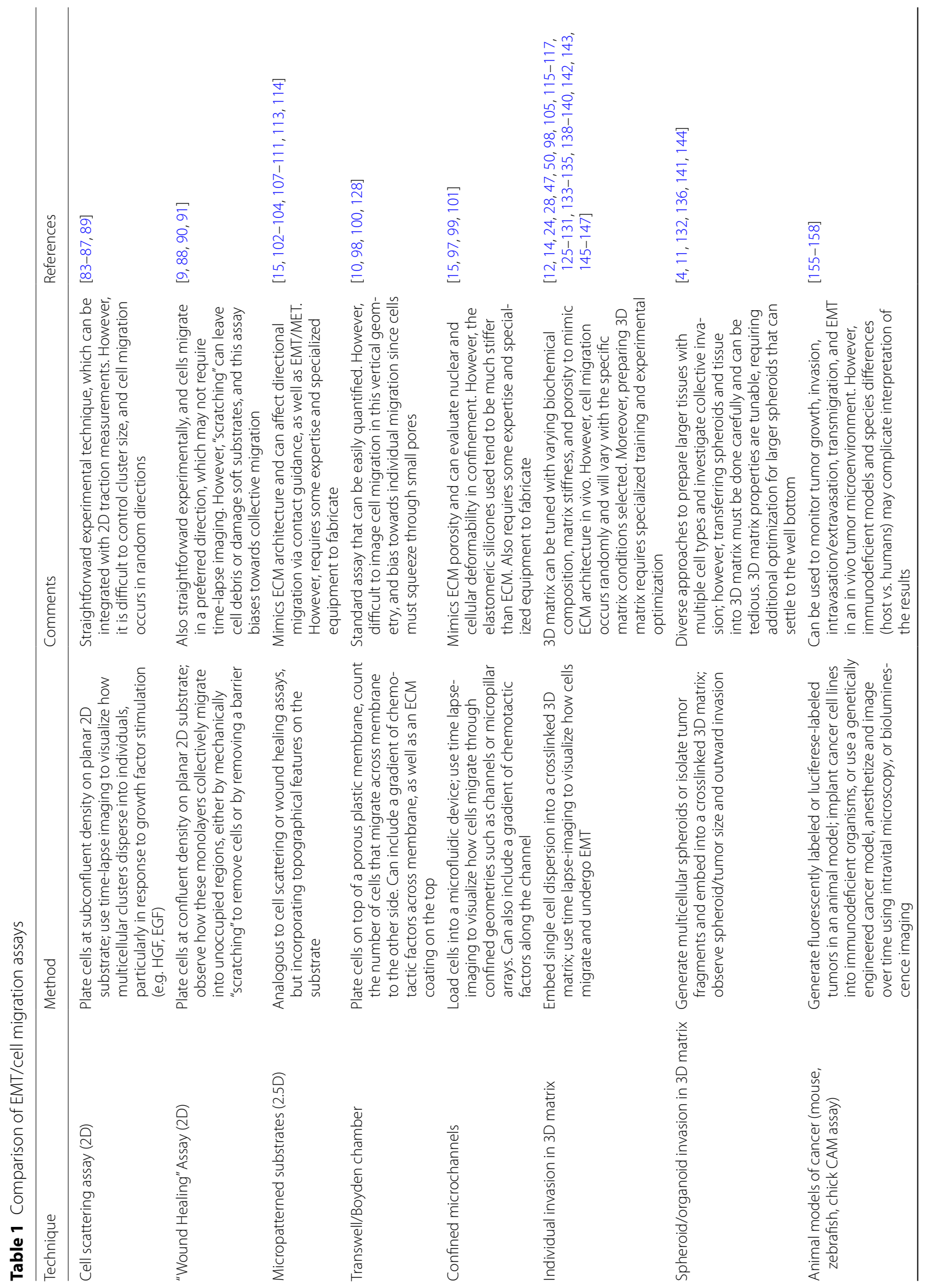




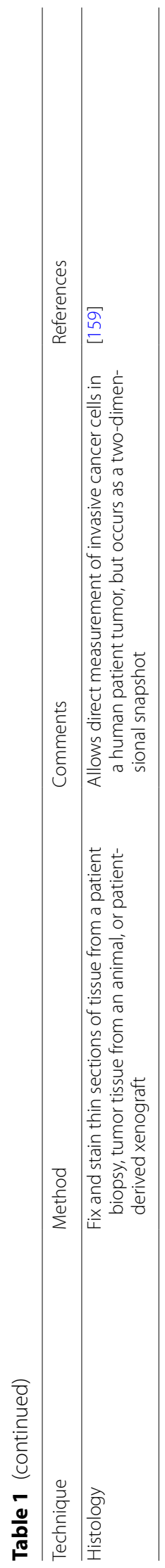


increased motility in response to HGF is sufficient to rupture cell-cell junctions without associated downregulation of E-cadherin [85]. Similarly, slowed cell motility in reduced EGF results in multicellular cluster formation and collective behaviors [89], reminiscent of an MET. Existing traction force microscopy methods are only capable of inferring cell-cell forces from cell-matrix tractions for small cell clusters, where all cells are in contact with the underlying $2 \mathrm{D}$ substrate. It remains challenging to measure forces deep within 3D clusters, and may require the use of molecular force sensors or embedded probe particles that are compliant [160]. Nevertheless, there is increasing evidence that extensive cell-cell contacts (i.e. near confluency) that maintain apicobasal polarity restrict EMT activation, both in 2D [161, 162] and in 3D [140]. Biomaterial patterning techniques may also be employed to define the shape of multicellular clusters, in order to indirectly modulate the configuration of cell-cell adhesions for any given cell $[163,164]$.

\section{Probing intracellular mechanics and the cytoskeleton}

EMT is associated with the loss of keratin and the gain of vimentin intermediate filaments, although the functional role of these cytoskeletal proteins is still being investigated. Remarkably, microinjection of vimentin into mammary epithelial cells (MCF-7) is sufficient to drive morphological elongation, analogous to EMT [93]. The presence of vimentin within the cytoskeleton also protects the cell against externally applied stretch [94], and provides structural integrity to limit nuclear damage as cells traverse through confined spaces [97-99]. An ongoing challenge for this field is to mechanically probe subcellular mechanics, which are confounded by different contributions of thermal forces and the activity of molecular motors $[165,166]$. Indeed, Gupta et al. showed that cell mechanical properties can vary considerably across transverse and longitudinal directions for elongated cells confined to micropatterns on planar 2D substrates [167]. Intracellular mechanics are even more challenging to probe in situ for cells embedded in 3D matrix, since they are inaccessible to most mechanical characterization techniques based on direct contact.

Guo et al. recently demonstrated that intracellular stiffness is inversely proportional to cell and nuclear size [66]. In particular, mammary epithelial cells at the core of a multicellular cluster were smaller and stiffer, while cells at the periphery were larger and softer [142]. Qualitatively similar trends were observed for nuclear size in breast tumors from human patients. This phenomenon will require further validation in human patients, since nuclear and cell morphologies are typically dysregulated during tumor progression. Nevertheless, tracking how these morphological features vary in space and time could give new insights into cell stiffness. More generally, the improved control and visualization of cytoskeletal structure can be coupled with functional assays of cell stiffness and tractions for both individuals and multicellular groups. An interesting possibility is the use of machine learning and convolutional neural networks to profile distinct patterns of cytoskeletal organization that correlate with enhanced invasion and EMT [168], both in these bioengineered models as well as for intravital imaging and patient histology. Moreover, computational modeling can approximate single cells as discrete "agents" with some representation of intracellular signaling networks, along with cell and matrix mechanics (see recent reviews in $[169,170]$ ). These agents can further interact with a surrounding microenvironment that models hypoxia, chemotactic gradients, etc. at coarser length scales (i.e. a continuum treatment using partial differential equations), for better computational efficiency (see review in [171]). Thus, higher resolution experimental measurements in space and time can be refined by computer vision and inform quantitative simulations to make testable predictions about cancer cell biology.

\section{EMT in cancer metastasis}

EMT and vimentin expression play an important role in directed cell migration, which is a crucial step in tumor invasion [8]. In particular, EMT is often observed at invasion fronts in vitro [88, 97, 113, 142], consistent with in vivo observations of EMT at the periphery of human patient tumors [172]. Vimentin plays an important role in coordinating focal adhesions and enhancing actomyosin contractility [173], as well as invadopodia to degrade the basement membrane [82]. However, the role of vimentin and EMT for cancer cells that intravasate into the bloodstream and extravasate into the metastatic site remains unresolved. It is likely that vimentin can protect the cell nucleus as cells traverse confined spaces within capillaries, consistent with measurements of migratory cells in microchannels $[98,99]$. Vimentin also supports tubulinbased membrane protrusion called "microtentacles" that facilitate cancer cell adhesion and arrest on the vasculature [174]. However, EMT has not been proven to be essential for metastatic cancer in humans [7].

Although transitions between epithelial and mesenchymal phenotype are tightly controlled in development and wound healing, it is conceivable that a complete spectrum between epithelial and mesenchymal states occurs in tumor progression (i.e. cancer as a caricature of development). Yu et al. characterized circulating tumor cells (CTCs) from breast cancer patients using RNA-in situ hybridization, showing distinct states with only epithelial transcripts, "hybrids" with both epithelial and mesenchymal transcripts, or only mesenchymal 
transcripts [175]. Biomarkers of this "hybrid state" could manifest as co-expression of vimentin and keratin intermediate filaments. Pioneering work by Hendrix and coworkers investigated genetic co-expression of keratin (K8 and K18) with vimentin in breast cancer and melanoma cell lines, showing some increase in 3D invasion due to altered integrin expression [176, 177]. Recently, Pastushenko et al. identified a "partial EMT" state that expresses both vimentin and keratin-14 (but not EpCAM), with increased metastatic potential in mouse models of melanoma (KRas ${ }^{\mathrm{LSL}-G 12 \mathrm{D}} \mathrm{p} 53^{\mathrm{f} / \mathrm{fl}}$ ) and breast cancer (MMTVPyMT) [178]. Indeed, a subpopulation of tumor cells has been previously observed with co-expression of vimentin and keratin in colorectal cancer patients ("tumor budding") [179], as well as from metastatic cancer cells in breast cancer patients [180, 181].

CTCs can be isolated from peripheral blood as multicellular clusters, raising the intriguing possibility is that groups of cells with varying epithelial or mesenchymal states can further cooperate at varying stages of metastasis. Aceto et al. showed that CTC clusters exhibited 50 -fold enhanced metastatic potential relative to single CTCs in mouse models, suggesting that disseminated micrometastases are often polyclonal [182]. Cheung et al. [183] have highlighted the role of keratin-14 in (vimentin negative) epithelial leader cells as well as adhesion between CTCs within clusters [184] in a genetically engineered mouse model of breast cancer (MMTVPyMT). Overall, the functional role of keratin-14 remains poorly understood, but could conceivably substitute for vimentin to coordinate cell migration and protect the cell nucleus, and merits further investigation at single cell resolution. More nuanced genetic manipulation of signaling pathways in small animal models may enable deeper understanding of functional phenotypes, which can be corroborated back to human patient data.

EMT may occur transiently during different states of tumor progression. In particular, EMT is associated with early dissemination in a number of genetically engineered mouse models [185-187]. One potential explanation is that EMT may be advantageous for tumor cells in inhospitable microenvironments, particularly to establish a pre-metastatic niche [188], evade immune cells [189, 190], or resist drug treatment. Indeed, Fischer et al. and Zheng et al. have reported that EMT is dispensable for metastasis in mouse models but associated with chemoresistance [191, 192]. Similarly, Yu et al. observed more mesenchymal states and CTC clusters as patients exhibited increased drug resistance. Quantitative profiling of cell morphology, EMT biomarker expression, and mechanophenotype have been used to capture population level heterogeneity and plasticity associated with EMT in vitro $[143,162]$, and such methods may be useful to interrogate patient samples to guide precision medicine in the future. For instance, Navas et al. [193] designed a quantitative immunofluorescence assay to evaluate the EMT status of patient samples, which revealed a high degree of diversity across patients and carcinoma type. Notably, some patients with advanced disease exhibited highly heterogeneous mixtures of epithelial, partial EMT, and mesenchymal subpopulations, the abundance of which tended to shift after drug treatment toward an increasing mesenchymal fraction. Nevertheless, tumor cells with mesenchymal biomarkers are relatively uncommon at metastatic sites, which could occur since they are outcompeted by faster proliferating epithelial cells once selection pressure is removed. Alternatively, it has been proposed that tumor cells can undergo a reverse MET at a metastatic site, which remains challenging to experimentally verify [7].

Ultimately, improved temporal resolution of single cell states at varying steps of the metastatic cascade are required to elucidate the role of EMT. Intravital microscopy has emerged as a powerful approach for visualizing fluorescently labeled tumor cells within an in vivo tumor microenvironment (reviewed in [156]). In mice, surgery is performed to generate skin-flaps for short-term timelapses or optical imaging windows for long-term studies to enable intravital microscopy [194]. Alternatively, spontaneous and experimental metastasis assays may be conducted in zebrafish or the chick embryo (chick chorioallantoic membrane assay, "CAM assay"), which provide a more facile and scalable approach for monitoring tumor-stroma interactions [158]. EMT and individual invasion are frequently observed in xenografts and genetically engineered mouse models [195-198], although increased collective invasion has been observed by implantation of multicellular spheroids [199] or organoids [184]. Thus, EMT and invasion phenotype may also vary with cell-cell and cell-matrix interactions in vivo [200], as well as with tissue origin, necessitating more nuanced phenotypic and genetic definitions that can be systematically and rigorously tested [2]. Rigorous validation of cell migration and EMT in bioengineered systems against animal models and patient data should occur not only for genetic and transcriptional profiles, but also functional phenotypes as well.

\section{Conclusion}

Bioengineering approaches enable new insights into EMT and the cytoskeleton through a combination of higher resolution measurement and highly consistent assay geometries. In this review, we highlight our selection of recent results that highlight new capabilities and address unresolved questions in this field. First, cells cultured on planar substrates exhibit coordinated 
behaviors, with leader cells emerging through EMTlike processes. Second, localized probing of vimentin networks reveals that they enhance the stretchability of cells under large deformations. Indeed, cells that express vimentin can better protect their nucleus and squeeze through highly confined spaces during migration or proliferation. Third, cells cultured on topographically patterned features adhere in a spatially asymmetric fashion, resulting in a reorganization of the cytoskeleton and cell-cell adhesions. Highly aligned features typically result in cell elongation and directional migration along these "tracks," analogous to EMT. However, fractal-like topographies that limit cell-matrix adhesions can drive mesenchymal cell types to undergo an MET and express epithelial biomarkers. Finally, multicellular clusters cultured in compliant tri-dimensional matrix can disorganize and disseminate with spatially heterogeneous cell stiffness and tractions. These collective behaviors are spatially coordinated across the population by biochemical and mechanical signals. Nevertheless, when matrix remodeling is impeded, mesenchymal cells can undergo an MET and form compact epithelial acini. Overall, these technologies could be utilized for rapid measurements of patient samples (i.e. organoids), mapping tumor transitions at single cell resolution over space and time, which cannot be directly resolved in human patients. Moreover, biomimetic systems enable fundamental insights into how cells behave in well controlled physical microenvironments, and could test drug response at higher throughput than xenograft models. Ultimately, these new technological capabilities will be essential to reveal exceptional cells and rare events that underlie both EMT and tumor metastasis in human patients.

\footnotetext{
Abbreviations

2D:: Two dimensional; 3D:: Three dimensional; APC:: Adenomatous polyposis coli; CAM:: Chorioallantoic membrane; CTC:: Circulating tumor cell; DIA1:: Formin diaphanous 1; EGF:: Epidermal growth factor; EMT:: Epithelial-mesenchymal transition; GSK-3:: Glycogen synthase kinase 3; HA:: Hyaluronic acid; HGF:: Hepatocyte growth factor; ICAM1:: Intercellular adhesion molecule 1; LIMK:: LIM kinase; MDCK:: Madin-Darby canine kidney; $\mathbf{m E F}::$ Mouse embryonic fibroblasts; MET:: Mesenchymal-epithelial transitions; MMP:: Matrix metalloproteinase; PECAM1:: Platelet and endothelial cell adhesion molecule 1; ROCK:: Rho-associated Kinase; TAZ:: Transcriptional coactivator with PDZbinding motif; TGF- $\beta$ :: Transforming growth factor beta; YAP.: Yes-associated protein; ZEB1/2:: Zinc finger E-box-binding homeobox 1/2.
}

\section{Acknowledgements}

We apologize to authors whose work could not be included in this review due to space constraints. We thank A.S. Brodsky, W. El-Deiry, and J.X. Tang for helpful comments.

\section{Author's contributions}

SEL and IYW conceptualized the manuscript; all authors wrote the manuscript. All authors read and approved the final manuscript.

\section{Declaration}

Ethical approval and consent to participate

Not applicable.

\section{Consent for publication}

Not applicable.

\section{Availability of supporting data \\ Not applicable.}

\section{Competing interests}

The authors declare that they have no competing interests.

\section{Funding}

We acknowledge prior funding for this work from the National Institutes of Health (T32ES007272, R21CA212932, P30GM110759, U01CA202123, TL1TR003019, R01GM140108).

\section{Author details}

${ }^{1}$ Department of Chemical and Biological Engineering, Princeton University, William St, Princeton, NJ 08544, USA. ${ }^{2}$ School of Engineering, Center for Biomedical Engineering, and Joint Program in Cancer Biology, Brown University, 184 Hope St Box D, Providence, RI 02912, USA. ${ }^{3}$ Department of Mechanical Engineering, MIT, 77 Massachusetts Ave, Cambridge, MA 02139, USA.

Received: 30 October 2020 Accepted: 26 January 2021

Published online: 10 March 2021

\section{References}

1. Nieto MA, Huang RY-J, Jackson RA, Thiery JP. EMT: 2016. Cell. 2016;166(1):21-45.

2. Yang J, Antin P, Berx G, Blanpain C, Brabletz T, Bronner M, Campbell K, Cano A, Casanova J, Christofori G, Dedhar S, Derynck R, Ford HL, Fuxe J, García de Herreros A, Goodall GJ, Hadjantonakis A-K, Huang RJY, Kalcheim C, Kalluri R, Kang Y, Khew-Goodall Y, Levine H, Liu J, Longmore GD, Mani SA, Massagué J, Mayor R, McClay D, Mostov KE, Newgreen DF, Nieto MA, Puisieux A, Runyan R, Savagner P, Stanger B, Stemmler MP, Takahashi Y, Takeichi M, Theveneau E, Thiery JP, Thompson EW, Weinberg RA, Williams ED, Xing J, Zhou BP, Sheng G. EMT International Association (TEMTIA): guidelines and definitions for research on epithelial-mesenchymal transition. Nat Rev Mole Cell Biol. 2020;21(6):341-52. https://doi.org/10.1038/s41580-020-0237-9.

3. Yilmaz M, Christofori G. EMT, the cytoskeleton, and cancer cell invasion. Cancer Metastasis Rev. 2009;28(1-2):15-33. https://doi.org/10.1007/ s10555-008-9169-0.

4. Greenburg G, Hay ED. Epithelia suspended in collagen gels can lose polarity and express characteristics of migrating mesenchymal cells. J Cell Biol. 1982;95(1):333-9. https://doi.org/10.1083/jcb.95.1.333.

5. Leight $\mathrm{LL}$, Drain AP, Weaver VM. Extracellular matrix remodeling and stiffening modulate tumor phenotype and treatment response. Annu Rev Cancer Biol. 2017;1 (1):313-34.

6. Eriksson JE, Dechat T, Grin B, Helfand B, Mendez M, Pallari H-M, Goldman RD. Introducing intermediate filaments: from discovery to disease. J Clin Investig. 2009:119(7):1763-71. https://doi.org/10.1172/JC138339.

7. Williams ED, Gao D, Redfern A, Thompson EW. Controversies around epithelial-mesenchymal plasticity in cancer metastasis. Nat Rev Cancer. 2019;19(12):716-32. https://doi.org/10.1038/s41568-019-0213-x.

8. Friedl P, Locker J, Sahai E, Segall JE. Classifying collective cancer cell invasion. Nat Cell Biol. 2012;14(8):777-83. https://doi.org/10.1038/ ncb2548.

9. Ashby WJ, Zijlstra A. Established and novel methods of interrogating two-dimensional cell migration. Integr Biol. 2012;4(11):1338-50.

10. Boyden $\mathrm{S}$. The chemotactic effect of mixtures of antibody and antigen on polymorphonuclear leucocytes. J Exp Med. 1962;115(3):453-66. https://doi.org/10.1084/jem.115.3.453.

11. Simian M, Bissell MJ. Organoids: a historical perspective of thinking in three dimensions. J Cell Biol. 2017;216(1):31-40. https://doi. org/10.1083/jcb.201610056. 
12. Leggett SE, Khoo AS, Wong IY. Multicellular tumor invasion and plasticity in biomimetic materials. Biomater Sci. 2017;5(8):1460-79. https://doi. org/10.1039/C7BM00272F.

13. Debnath J, Brugge JS. Modelling glandular epithelial cancers in threedimensional cultures. Nat Rev Cancer. 2005;5(9):675-88. https://doi. org/10.1038/nrc1695.

14. Beri P, Matte BF, Fattet L, Kim D, Yang J, Engler AJ. Biomaterials to model and measure epithelial cancers. Nat Rev Mater. 2018. https://doi. org/10.1038/s41578-018-0051-6.

15. Paul CD, Mistriotis $P$, Konstantopoulos K. Cancer cell motility: lessons from migration in confined spaces. Nat Rev Cancer. 2017;17(2):131-40 https://doi.org/10.1038/nrc.2016.123.

16. Marusyk A, Janiszewska M, Polyak K. Intratumor heterogeneity: the rosetta stone of therapy resistance. Cancer Cell. 2020;37(4):471-84. https://doi.org/10.1016/j.ccell.2020.03.007.

17. Skylaki S, Hilsenbeck O, Schroeder T. Challenges in long-term imaging and quantification of single-cell dynamics. Nat Biotechnol. 2016;34(11):1137-44. https://doi.org/10.1038/nbt.3713.

18. Fletcher DA, Mullins RD. Cell mechanics and the cytoskeleton. Nature. 2010:463(7280):485-92.

19. Alibert C, Goud B, Manneville J-B. Are cancer cells really softer than normal cells? Biol cell. 2017;109(5):167-89. https://doi.org/10.1111/ boc. 201600078 .

20. Polacheck WJ, Chen CS. Measuring cell-generated forces: a guide to the available tools. Nat Methods. 2016;13(5):415-23. https://doi. org/10.1038/nmeth.3834.

21. Trepat X, Sahai E. Mesoscale physical principles of collective cell organization. Nat Phys. 2018. https://doi.org/10.1038/s41567-018-0194-9.

22. Lamouille $\mathrm{S}, \mathrm{Xu}$ J, Derynck R. Molecular mechanisms of epithelial-mesenchymal transition. Nat Rev Mol Cell Biol. 2014;15(3):178-96.

23. Zaravinos A. The regulatory role of MicroRNAs in EMT and cancer. J Oncol. 2015;2015(4):1-13.

24. Bryant DM, Mostov KE. From cells to organs: building polarized tissue. Nat Rev Mole Cell Biol. 2008;9(11):887-901.

25. Siegel RL, Miller KD, Jemal A. Cancer statistics, 2019. CA Cancer J Clin. 2019;69(1):7-34.

26. Svitkina T. The actin cytoskeleton and actin-based motility. Cold Spring Harb Perspect Biol. 2018;10(1):a018267.

27. Jones JCR, Kam CY, Harmon RM, Woychek AV, Hopkinson SB, Green KJ. Intermediate filaments and the plasma membrane. Cold Spring Harb Perspect Biol. 2017;9(1):a025866.

28. Overholtzer M, Zhang J, Smolen GA, Muir B, Li W, Sgroi DC, Deng C-X, Brugge JS, Haber DA. Transforming properties of YAP, a candidate oncogene on the chromosome 11q22 amplicon. Proc Natl Acad Sci USA. 2006;103(33):12405-10.

29. Panciera T, Azzolin L, Cordenonsi M, Piccolo S. Mechanobiology of YAP and TAZ in physiology and disease. Nat Rev Mol Cell Biol. 2017;18(12):758-70.

30. Ma S, Meng Z, Chen R, Guan K-L. The Hippo pathway: biology and pathophysiology. Annu Rev Biochem. 2019;88:577-604. https://doi. org/10.1146/annurev-biochem-013118-111829.

31. Zanconato F, Cordenonsi M, Piccolo S. YAP and TAZ: a signalling hub of the tumour microenvironment. Nat Rev Cancer. 2019;19(8):454-64.

32. Mayor R, Etienne-Manneville $\mathrm{S}$. The front and rear of collective cell migration. Nat Rev Mol Cell Biol. 2016;17(2):97-109.

33. Campbell K, Casanova J. A common framework for EMT and collective cell migration. Development. 2016;143(23):4291-300.

34. Lowery J, Kuczmarski ER, Herrmann H, Goldman RD. Intermediate filaments play a pivotal role in regulating cell architecture and function. J Biol Chem. 2015;290(28):17145-53.

35. Pegoraro AF, Janmey P, Weitz DA. Mechanical properties of the cytoskeleton and cells. Cold Spring Harb Perspect Biol. 2017;9(11):a022038.

36. Broedersz CP, MacKintosh FC. Modeling semiflexible polymer networks. Rev Mod Phys. 2014;86:995-1036. https://doi.org/10.1103/RevModPhys .86 .995 .

37. Storm C, Pastore JJ, Mackintosh FC, Lubensky TC, Janmey PA. Nonlinear elasticity in biological gels. Nature. 2005;435(7039):191-4.

38. MacKintosh F, Käs J, Janmey P. Elasticity of semiflexible biopolymer networks. Phys Rev Lett. 1995;75(24):4425-8.
39. Onck PR, Koeman T, van Dillen T, van der Giessen E. Alternative explanation of stiffening in cross-linked semiflexible networks. Phys Rev Lett. 2005;95(17):178102.

40. Janmey PA, Euteneuer U, Traub P, Schliwa M. Viscoelastic properties of vimentin compared with other filamentous biopolymer networks. J Cell Biol. 1991;113(1):155-60.

41. Gittes F, Mickey B, Nettleton J, Howard J. Flexural rigidity of microtubules and actin filaments measured from thermal fluctuations in shape. J Cell Biol. 1993;120(4):923-34.

42. Murrell M, Oakes PW, Lenz M, Gardel ML. Forcing cells into shape: the mechanics of actomyosin contractility. Nat Rev Mol Cell Biol. 2015;16(8):486-98.

43. Lauffenburger DA, Horwitz AF. Cell migration: a physically integrated molecular process. Cell. 1996;84(3):359-69.

44. Haga RB, Ridley AJ. Rho GTPases: regulation and roles in cancer cell biology. Small GTPases. 2016;7(4):207-21. https://doi.org/10.1080/21541 248.2016.1232583.

45. Bhowmick NA, Ghiassi M, Bakin A, Aakre M, Lundquist CA, Engel ME, Arteaga CL, Moses HL. Transforming growth factor-beta1 mediates epithelial to mesenchymal transdifferentiation through a RhoA-dependent mechanism. MBoC. 2001;12(1):27-36. https://doi.org/10.1091/ mbc.12.1.27.

46. Geneste O, Copeland JW, Treisman R. LIM kinase and Diaphanous cooperate to regulate serum response factor and actin dynamics. J Cell Biol. 2002;157(5):831-8. https://doi.org/10.1083/jcb.200203126.

47. Fessenden TB, Beckham Y, Perez-Neut M, Ramirez-San Juan G, Chourasia AH, Macleod KF, Oakes PW, Gardel ML. Dia1-dependent adhesions are required by epithelial tissues to initiate invasion. J Cell Biol. 2018;217(4):1485-502. https://doi.org/10.1083/jcb.201703145.

48. Nelson WJ. Remodeling epithelial cell organization: transitions between front-rear and apical-basal polarity. Cold Spring Harb Perspect Biol. 2009;1 (1):000513. https://doi.org/10.1101/cshperspect.a000513.

49. Noren NK, Liu BP, Burridge K, Kreft B. p120 catenin regulates the actin cytoskeleton via Rho family GTPases. J Cell Biol. 2000;150(3):567-80. https://doi.org/10.1083/jcb.150.3.567.

50. Zhan L, Rosenberg A, Bergami KC, Yu M, Xuan Z, Jaffe AB, Allred C, Muthuswamy SK. Deregulation of scribble promotes mammary tumorigenesis and reveals a role for cell polarity in carcinoma. Cell. 2008;135(5):865-78. https://doi.org/10.1016/j.cell.2008.09.045.

51. Wittmann T, Bokoch GM, Waterman-Storer CM. Regulation of leading edge microtubule and actin dynamics downstream of Rac1. J Cell Biol. 2003;161(5):845-51. https://doi.org/10.1083/jcb.200303082.

52. Yang $X$, Pursell B, Lu S, Chang T-K, Mercurio AM. Regulation of beta 4-integrin expression by epigenetic modifications in the mammary gland and during the epithelial-to-mesenchymal transition. J Cell Sci. 2009;122(Pt 14):2473-80. https://doi.org/10.1242/jcs.049148.

53. Mise N, Savai R, Yu H, Schwarz J, Kaminski N, Eickelberg O. Zyxin is a transforming growth factor- $\beta$ (TGF- $\beta$ )/Smad3 target gene that regulates lung cancer cell motility via integrin $a 5 \beta 1$. J Biol Chem. 2012;287(37):31393-405. https://doi.org/10.1074/jbc.M1 12.357624.

54. Koenig A, Mueller C, Hasel C, Adler G, Menke A. Collagen type I induces disruption of E-cadherin-mediated cell-cell contacts and promotes proliferation of pancreatic carcinoma cells. Cancer Res. 2006;66(9):4662-71. https://doi.org/10.1158/0008-5472.CAN-05-2804.

55. Xu H, Bihan D, Chang F, Huang PH, Farndale RW, Leitinger B. Discoidin domain receptors promote $\alpha 1 \beta 1$ - and $a 2 \beta 1$-integrin mediated cell adhesion to collagen by enhancing integrin activation. PLOS ONE. 2012;7(12):52209. https://doi.org/10.1371/journal.pone.0052209.

56. Nisticò P, Bissell MJ, Radisky DC. Epithelial-mesenchymal transition: general principles and pathological relevance with special emphasis on the role of matrix metalloproteinases. Cold Spring Harb Perspect Biol. 2012. https://doi.org/10.1101/cshperspect.a011908.

57. Wolf K, Friedl P. Extracellular matrix determinants of proteolytic and non-proteolytic cell migration. Trends Cell Biol. 2011;21(12):736-44.

58. Schweizer J, Bowden PE, Coulombe PA, Langbein L, Lane EB, Magin TM, Maltais L, Omary MB, Parry DAD, Rogers MA, Wright MW. New consensus nomenclature for mammalian keratins. J Cell Biol. 2006;174(2):16974. https://doi.org/10.1083/jcb.200603161.

59. Kreplak L, Bär H, Leterrier JF, Herrmann H, Aebi U. Exploring the mechanical behavior of single intermediate filaments. J Mol Biol. 2005;354(3):569-77. 
60. Herrmann $\mathrm{H}, \mathrm{Bär} \mathrm{H}, \mathrm{Kreplak} L$, Strelkov SV, Aebi U. Intermediate filaments: from cell architecture to nanomechanics. Nat Rev Mol Cell Biol. 2007:8(7):562-73.

61. Lin Y-C, Broedersz CP, Rowat AC, Wedig T, Herrmann H, Mackintosh FC, Weitz DA. Divalent cations crosslink vimentin intermediate filament tail domains to regulate network mechanics. J Mol Biol. 2010;399(4):63744. https://doi.org/10.1016/j.jmb.2010.04.054

62. Yamada S, Wirtz D, Coulombe PA. The mechanical properties of simple epithelial keratins 8 and 18: discriminating between interfacial and bulk elasticities. J Struct Biol. 2003;143(1):45-55. https://doi.org/10.1016/ S1047-8477(03)00101-1.

63. Pawelzyk P, Mücke N, Herrmann H, Willenbacher N. Attractive interactions among intermediate filaments determine network mechanics in vitro. PLOS ONE. 2014;9(4):93194-9. https://doi.org/10.1371/journ al.pone.0093194.

64. Lin Y-C, Yao NY, Broedersz CP, Herrmann H, MacKintosh FC, Weitz DA Origins of elasticity in intermediate filament networks. Phys Rev Lett. 2010;104(5):058101. https://doi.org/10.1103/PhysRevLett.104.058101.

65. Wu H, Shen Y, Wang D, Herrmann H, Goldman RD, Weitz DA. Effect of divalent cations on the structure and mechanics of vimentin intermediate filaments. Biophys J. 2020;119(1):55-64. https://doi.org/10.1016/j. bpj.2020.05.016.

66. Guo M, Pegoraro AF, Mao A, Zhou EH, Arany PR, Han Y, Burnette DT, Jensen MH, Kasza KE, Moore JR, Mackintosh FC, Fredberg JJ, Mooney DJ, Lippincott-Schwartz J, Weitz DA. Cell volume change through water efflux impacts cell stiffness and stem cell fate. Proc Natl Acad Sci USA. 2017:114(41):8618-27.

67. Coulombe PA, Hutton ME, Letai A, Hebert A, Paller AS, Fuchs E. Point mutations in human keratin 14 genes of epidermolysis bullosa simplex patients: genetic and functional analyses. Cell. 1991;66(6):1301-11.

68. Ramms L, Fabris G, Windoffer R, Schwarz N, Springer R, Zhou C, Lazar J, Stiefel S, Hersch N, Schnakenberg U, Magin TM, Leube RE, Merkel R, Hoffmann B. Keratins as the main component for the mechanical integrity of keratinocytes. Proc Natl Acad Sci USA. 2013;110(46):18513-8. https://doi.org/10.1073/pnas.1313491110.

69. Seltmann K, Fritsch AW, Käs JA, Magin TM. Keratins significantly contribute to cell stiffness and impact invasive behavior. Proc Natl Acad Sci USA. 2013;110(46):18507-12. https://doi.org/10.1073/pnas.1310493110.

70. Fortier A-M, Asselin E, Cadrin M. Keratin 8 and 18 loss in epithelial cancer cells increases collective cell migration and cisplatin sensitivity through claudin1 up-regulation. J Biol Chem. 2013;288(16):11555-71. https://doi.org/10.1074/jbc.M112.428920.

71. König K, Meder L, Kröger C, Diehl L, Florin A, Rommerscheidt-Fuss U, Kahl P, Wardelmann E, Magin TM, Buettner R, Heukamp LC. Loss of the keratin cytoskeleton is not sufficient to induce epithelial mesenchymal transition in a novel KRAS driven sporadic lung cancer mouse model. PLoS ONE. 2013;8(3):e57996. https://doi.org/10.1371/journ al.pone.0057996.

72. Eckes B, Dogic D, Colucci-Guyon E, Wang N, Maniotis A, Ingber D, Merckling A, Langa F, Aumailley M, Delouvée A, Koteliansky V, Babinet C, Krieg T. Impaired mechanical stability, migration and contractile capacity in vimentin-deficient fibroblasts. J Cell Sci. 1998;111(Pt 13):1897-907.

73. Eckes B, Colucci-Guyon E, Smola H, Nodder S, Babinet C, Krieg T, Martin $P$. Impaired wound healing in embryonic and adult mice lacking vimentin. J Cell Sci. 2000;113(Pt 13):2455-62.

74. Brouhard GJ, Rice LM. Microtubule dynamics: an interplay of biochemistry and mechanics. Nat Rev Mol Cell Biol. 2018;19:1-13.

75. Burgstaller G, Gregor M, Winter L, Wiche G. Keeping the vimentin network under control: cell-matrix adhesion-associated plectin $1 \mathrm{f}$ affects cell shape and polarity of fibroblasts. Mol Biol Cell. 2010;21(19):3362-75.

76. Kim H, Nakamura F, Lee W, Hong C, Pérez-Sala D, McCulloch CA. Regulation of cell adhesion to collagen via $\beta 1$ integrins is dependent on interactions of filamin A with vimentin and protein kinase $C$ epsilon. Exp Cell Res. 2010;316(11):1829-44.

77. Sakamoto Y, Boëda B, Etienne-Manneville S. APC binds intermediate filaments and is required for their reorganization during cell migration. J Cell Biol. 2013;200(3):249-58.

78. Helfand BT, Mendez MG, Murthy SNP, Shumaker DK, Grin B, Mahammad S, Aebi U, Wedig T, Wu Yl, Hahn KM, Inagaki M, Herrmann H, Goldman RD. Vimentin organization modulates the formation of lamellipodia. Mol Biol Cell. 2011;22(8):1274-89.
79. Vohnoutka RB, Gulvady AC, Goreczny G, Alpha K, Handelman SK, Sexton JZ, Turner CE. The focal adhesion scaffold protein Hic-5 regulates vimentin organization in fibroblasts. MBoC. 2019;30(25):3037-56. https ://doi.org/10.1091/mbc.E19-08-0442.

80. Gulvady AC, Dubois F, Deakin NO, Goreczny GJ, Turner CE. Hic-5 expression is a major indicator of cancer cell morphology, migration, and plasticity in three-dimensional matrices. MBoC. 2018;29(13):1704-17. https://doi.org/10.1091/mbc.E18-02-0092.

81. De Pascalis C, Pérez-González C, Seetharaman S, Boëda B, Vianay B, Burute M, Leduc C, Borghi N, Trepat X, Etienne-Manneville S. Intermediate filaments control collective migration by restricting traction forces and sustaining cell-cell contacts. J Cell Biol. 2018;217(9):3031-44.

82. Schoumacher M, Goldman RD, Louvard D, Vignjevic DM. Actin, microtubules, and vimentin intermediate filaments cooperate for elongation of invadopodia. J Cell Biol. 2010;189(3):541-56.

83. Stoker M, Gherardi E, Perryman M, Gray J. Scatter factor is a fibroblast-derived modulator of epithelial cell mobility. Nature. 1987;327(6119):239-42.

84. Clark P. Modulation of scatter factor/hepatocyte growth factor activity by cell-substratum adhesion. J Cell Sci. 1994;107(Pt 5):1265-75.

85. de Rooij J, Kerstens A, Danuser G, Schwartz MA, Waterman-Storer CM. Integrin-dependent actomyosin contraction regulates epithelial cell scattering. J Cell Biol. 2005;171(1):153-64.

86. Maruthamuthu V, Gardel ML. Protrusive activity guides changes in cell-cell tension during epithelial cell scattering. Biophys J. 2014;107(3):555-63.

87. Loerke D, le Duc Q, Blonk I, Kerstens A, Spanjaard E, Machacek M, Danuser G, de Rooij J. Quantitative imaging of epithelial cell scattering identifies specific inhibitors of cell motility and cell-cell dissociation. Sci Signal. 2012;5(231):5-5.

88. Gilles C, Polette M, Zahm JM, Tournier JM, Volders L, Foidart JM, Birembaut P. Vimentin contributes to human mammary epithelial cell migration. J Cell Sci. 1999;112(24):4615-25.

89. Leggett SE, Neronha ZJ, Bhaskar D, Sim JY, Perdikari TM, Wong IY. Motility-limited aggregation of mammary epithelial cells into fractallike clusters. Proc Natl Acad Sci USA. 2019;116(35):17298-306. https:// doi.org/10.1073/pnas.1905958116.

90. Riahi R, Sun J, Wang S, Long M, Zhang DD, Wong PK. Notch1-D\|l4 signalling and mechanical force regulate leader cell formation during collective cell migration. Nat Commun. 2019;6:1-11.

91. Reffay M, Parrini MC, Cochet-Escartin O, Ladoux B, Buguin A, Coscoy S, Amblard F, Camonis J, Silberzan P. Interplay of RhoA and mechanical forces in collective cell migration driven by leader cells. Nat Cell Biol. 2014;16(3):217-23.

92. Weitz DA, Oliveria M. Fractal structures formed by kinetic aggregation of aqueous gold colloids. Phys Rev Lett. 1984;52:1433-6. https://doi. org/10.1103/PhysRevLett.52.1433.

93. Mendez MG, Kojima SI, Goldman RD. Vimentin induces changes in cell shape, motility, and adhesion during the epithelial to mesenchymal transition. FASEB J. 2010;24(6):1838-51. https://doi.org/10.1096/fj.09151639 .

94. Hu J, Li Y, Hao Y, Zheng T, Gupta SK, Parada GA, Wu H, Lin S, Wang S, Zhao X, Goldman RD, Cai S, Guo M. High stretchability, strength, and toughness of living cells enabled by hyperelastic vimentin intermediate filaments. Proc Natl Acad Sci USA. 2019;116(35):17175-80. https://doi. org/10.1073/pnas.1903890116.

95. Guo M, Ehrlicher AJ, Mahammad S, Fabich H, Jensen MH, Moore JR, Fredberg JJ, Goldman RD, Weitz DA. The role of vimentin intermediate filaments in cortical and cytoplasmic mechanics. Biophys J. 2013:105(7):1562-8

96. Hu J, Jafari S, Han Y, Grodzinsky AJ, Cai S, Guo M. Size- and speeddependent mechanical behavior in living mammalian cytoplasm. Proc Natl Acad Sci USA. 2017;114(36):9529-34.

97. Wong IY, Javaid S, Wong EA, Perk S, Haber DA, Toner M, Irimia D. Collective and individual migration following the epithelial-mesenchymal transition. Nat Mater. 2014;13(11):1063-71. https://doi.org/10.1038/ nmat4062.

98. Patteson AE, Vahabikashi A, Pogoda K, Adam SA, Mandal K, Kittisopikul M, Sivagurunathan S, Goldman A, Goldman RD, Janmey PA. Vimentin protects cells against nuclear rupture and DNA damage during 
migration. J Cell Biol. 2019;218(12):4079-92. https://doi.org/10.1083/ jcb.201902046.

99. Patteson AE, Pogoda K, Byfield FJ, Mandal K, Ostrowska Podhorodecka Z, Charrier EE, Galie PA, Deptuła P, Bucki R, McCulloch CA, Janmey PA. Loss of vimentin enhances cell motility through small confining spaces. Small. 2019;15(50):1903180. https://doi.org/10.1002/smll.201903180.

100. Harada T, Swift J, Irianto J, Shin J-W, Spinler KR, Athirasala A, Diegmiller $R$, Dingal PCDP, Ivanovska IL, Discher DE. Nuclear lamin stiffness is a barrier to 3D migration, but softness can limit survival. J Cell Biol. 2014;204(5):669-82. https://doi.org/10.1083/jcb.201308029.

101. Denais CM, Gilbert RM, Isermann P, McGregor AL, te Lindert M, Weigelin B, Davidson PM, Friedl P, Wolf K, Lammerding J. Nuclear envelope rupture and repair during cancer cell migration. Science. 2016:352(6283):353-8. https://doi.org/10.1126/science.aad7297.

102. Kim D-H, Provenzano PP, Smith CL, Levchenko A. Matrix nanotopography as a regulator of cell function. J Cell Biol. 2012;197(3):351-60.

103. Cheng J, Jun Y, Qin J, Lee S-H. Electrospinning versus microfluidic spinning of functional fibers for biomedical applications. Biomaterials. 2017;114:121-43. https://doi.org/10.1016/j.biomaterials.2016.10.040.

104. Saha S, Duan X, Wu L, Lo P-K, Chen H, Wang Q. Electrospun fibrous scaffolds promote breast cancer cell alignment and epithelial-mesenchymal transition. Langmuir. 2012;28(4):2028-34. https://doi.org/10.1021/ la203846W.

105. Girard YK, Wang C, Ravi S, Howell MC, Mallela J, Alibrahim M, Green R, Hellermann G, Mohapatra SS, Mohapatra S. A 3D fibrous scaffold inducing tumoroids: a platform for anticancer drug development. PLOS ONE. 2013:8(10):75345. https://doi.org/10.1371/journal.pone.0075345.

106. Ravikrishnan A, Ozdemir T, Bah M, Baskerville KA, Shah SI, Rajasekaran AK, Jia X. Regulation of epithelial-to-mesenchymal transition using biomimetic fibrous scaffolds. ACS Appl Mater Interfaces. 2016;8(28):1791526. https://doi.org/10.1021/acsami.6b05646.

107. Jana A, Nookaew I, Singh J, Behkam B, Franco AT, Nain AS. Crosshatch nanofiber networks of tunable interfiber spacing induce plasticity in cell migration and cytoskeletal response. FASEB J. 2019;33(10):1061832. https://doi.org/10.1096/f.201900131R.

108. Wang Z, Tonderys D, Leggett SE, Williams EK, Kiani MT, Steinberg RS, Qiu $Y$, Wong IY, Hurt RH. Wrinkled, wavelength-tunable graphene-based surface topographies for directing cell alignment and morphology. Carbon. 2016;97:14-24. https://doi.org/10.1016/j.carbon.2015.03.040.

109. Jiang X, Takayama S, Qian X, Ostuni E, Wu H, Bowden N, LeDuc P, Ingber DE, Whitesides GM. Controlling mammalian cell spreading and cytoskeletal arrangement with conveniently fabricated continuous wavy features on poly(dimethylsiloxane). Langmuir. 2002;18(8):3273-80. https://doi.org/10.1021/la011668+.

110. Guvendiren M, Burdick JA. The control of stem cell morphology and differentiation by hydrogel surface wrinkles. Biomaterials. 2010;31(25):6511-8. https://doi.org/10.1016/j.biomaterials.2010.05.037.

111. Teixeira Al, Abrams GA, Bertics PJ, Murphy CJ, Nealey PF. Epithelial contact guidance on well-defined micro- and nanostructured substrates. J Cell Sci. 2003;1 16(10):1881-92. https://doi.org/10.1242/jcs.00383.

112. Ray A, Lee O, Win Z, Edwards RM, Alford PW, Kim D-H, Provenzano PP. Anisotropic forces from spatially constrained focal adhesions mediate contact guidance directed cell migration. Nat Commun. 2017;8:14923. https://doi.org/10.1038/ncomms14923.

113. Park J, Kim D-H, Shah SR, Kim H-N, Kshitiz Kim P, Quiñones-Hinojosa A, Levchenko A. Switch-like enhancement of epithelial- mesenchymal transition by YAP through feedback regulation of WT1 and Rho-family GTPases. Nat Commun. 2019. https://doi.org/10.1038/s41467-01910729-5.

114. Wang Z, Xia F, Labib M, Ahmadi M, Chen H, Das J, Ahmed SU, Angers S, Sargent EH, Kelley SO. Nanostructured architectures promote the mesenchymal-epithelial transition for invasive cells. ACS Nano. 2020;14(5):5324-36. https://doi.org/10.1021/acsnano.9b07350.

115. Nelson CM, Bissell MJ. Modeling dynamic reciprocity: engineering three-dimensional culture models of breast architecture, function, and neoplastic transformation. Semin Cancer Biol. 2005;15(5):342-52.

116. Paszek MJ, Zahir N, Johnson KR, Lakins JN, Rozenberg GI, Gefen A, Reinhart-King CA, Margulies SS, Dembo M, Boettiger D, Hammer DA, Weaver VM. Tensional homeostasis and the malignant phenotype. Cancer Cell. 2005;8(3):241-54.
117. Chaudhuri O, Koshy ST, Cunha C, Shin J-W, Verbeke CS, Allison KH, Mooney DJ. Extracellular matrix stiffness and composition jointly regulate the induction of malignant phenotypes in mammary epithelium. Nat Mater. 2014;13(10):970-8.

118. Roussos ET, Condeelis JS, Patsialou A. Chemotaxis in cancer. Nat Rev Cancer. 2011;11(8):573-87.

119. Oudin MJ, Weaver VM. Physical and chemical gradients in the tumor microenvironment regulate tumor cell invasion, migration, and metastasis. Cold Spring Harb Symp Quant Biol. 2016;81:189-205. https://doi. org/10.1101/sqb.2016.81.030817.

120. Park J, Kim D-H, Levchenko A. Topotaxis: a new mechanism of directed cell migration in topographic ECM gradients. Biophys. 2018:114(6):1257-63.

121. Polacheck WJ, German AE, Mammoto A, Ingber DE, Kamm RD. Mechanotransduction of fluid stresses governs 3D cell migration. Proc Natl Acad Sci. 2014;111(7):2447.

122. Piotrowski-Daspit AS, Tien J, Nelson CM. Interstitial fluid pressure regulates collective invasion in engineered human breast tumors via Snail, vimentin, and E-cadherin. Integrative biology: quantitative biosciences from nano to macro. 2016;8(3):319-31.

123. Li J, Lin F. Microfluidic devices for studying chemotaxis and electrotaxis. Trends Cell Biol. 2011;21(8):489-97.

124. Wolf K, Mazo I, Leung H, Engelke K, von Andrian UH, Deryugina El, Strongin AY, Bröcker E-B, Friedl P. Compensation mechanism in tumor cell migration. J Cell Biol. 2003;160(2):267-77.

125. Steinwachs J, Metzner C, Skodzek K, Lang N, Thievessen I, Mark C, Münster S, Aifantis KE, Fabry B. Three-dimensional force microscopy of cells in biopolymer networks. Nat Methods. 2015;13(2):171-6.

126. Hall MS, Alisafaei F, Ban E, Feng X, Hui C-Y, Shenoy VB, Wu M. Fibrous nonlinear elasticity enables positive mechanical feedback between cells and ECMs. Proc Natl Acad Sci. 2016;113(49):14043-8.

127. Han YL, Ronceray P, Xu G, Malandrino A, Kamm RD, Lenz M, Broedersz $\mathrm{CP}$, Guo M. Cell contraction induces long-ranged stress stiffening in the extracellular matrix. Proc Natl Acad Sci. 2018;115(16):4075-80.

128. Wolf $\mathrm{K}$, te Lindert $\mathrm{M}$, Krause $\mathrm{M}$, Alexander $\mathrm{S}$, te Riet J, Willis $\mathrm{AL}$, Hoffman RM, Figdor CG, Weiss SJ, Friedl P. Physical limits of cell migration: control by ECM space and nuclear deformation and tuning by proteolysis and traction force. J Cell Biol. 2013;201 (7):1069-84.

129. Carey SP, Martin KE, Reinhart-King CA. Three-dimensional collagen matrix induces a mechanosensitive invasive epithelial phenotype. Sci Rep. 2017;7(1):42088. https://doi.org/10.1038/srep42088.

130. Wei SC, Fattet L, Tsai JH, Guo Y, Pai VH, Majeski HE, Chen AC, Sah RL, TayIor SS, Engler AJ, Yang J. Matrix stiffness drives epithelial-mesenchymal transition and tumour metastasis through a TWIST1-G3BP2 mechanotransduction pathway. Nat Cell Biol. 2015;17(5):678-88. https://doi. org/10.1038/ncb3157.

131. Fattet $L$, Jung $H-Y$, Matsumoto MW, Aubol BE, Kumar $A$, Adams JA, Chen AC, Sah RL, Engler AJ, Pasquale EB, Yang J. Matrix rigidity controls epithelial-mesenchymal plasticity and tumor metastasis via a mechanoresponsive EPHA2/LYN complex. Dev Cell. 2020;54(3):302-3167. https://doi.org/10.1016/i.devcel.2020.05.031.

132. Lehmann S, te Boekhorst V, Odenthal J, Bianchi R, van Helvert S, Ikenberg K, llina O, Stoma S, Xandry J, Jiang L, Grenman R, Rudin M, Friedl P. Hypoxia induces a HIF-1-dependent transition from collective-to-amoeboid dissemination in epithelial cancer cells. Curr Biol. 2017;27(3):392-400. https://doi.org/10.1016/j.cub.2016.11.057.

133. Santos OF, Nigam SK. HGF-induced tubulogenesis and branching of epithelial cells is modulated by extracellular matrix and TGF-beta. Dev Biol. 1993;160(2):293-302. https://doi.org/10.1006/dbio.1993.1308.

134. Barros EJ, Santos OF, Matsumoto K, Nakamura T, Nigam SK. Differential tubulogenic and branching morphogenetic activities of growth factors: implications for epithelial tissue development. Proc Natl Acad Sci USA. 1995;92(10):4412-6. https://doi.org/10.1073/pnas.92.10.4412.

135. O'Brien LE, Tang K, Kats ES, Schutz-Geschwender A, Lipschutz JH, Mostov KE. ERK and MMPs sequentially regulate distinct stages of epithelial tubule development. Dev Cell. 2004;7(1):21-32. https://doi. org/10.1016/j.devcel.2004.06.001.

136. Nelson CM, Vanduijn MM, Inman JL, Fletcher DA, Bissell MJ. Tissue geometry determines sites of mammary branching morphogenesis in organotypic cultures. Science. 2006;314(5797):298-300. https://doi. org/10.1126/science.1131000. 
137. Lee K, Gjorevski N, Boghaert E, Radisky DC, Nelson CM. Snail1, Snail2, and $\mathrm{E} 47$ promote mammary epithelial branching morphogenesis. EMBO J. 2011;30(13):2662-74. https://doi.org/10.1038/emboj.2011.159.

138. Gill BJ, Gibbons DL, Roudsari LC, Saik JE, Rizvi ZH, Roybal JD, Kurie JM, West JL. A synthetic matrix with independently tunable biochemistry and mechanical properties to study epithelial morphogenesis and EMT in a lung adenocarcinoma model. Cancer Res. 2012;72(22):6013-23. https://doi.org/10.1158/0008-5472.CAN-12-0895.

139. Bidarra SJ, Oliveira P, Rocha S, Saraiva DP, Oliveira C, Barrias CC. A 3D in vitro model to explore the inter-conversion between epithelial and mesenchymal states during EMT and its reversion. Sci Rep. 2016;6:27072. https://doi.org/10.1038/srep27072.

140. Jung H-Y, Fattet L, Tsai JH, Kajimoto T, Chang Q, Newton AC, Yang J. Apical-basal polarity inhibits epithelial-mesenchymal transition and tumour metastasis by PAR-complex-mediated SNAI1 degradation. Nat Cell Biol. 2019;21(3):359-71.

141. Shamir ER, Pappalardo E, Jorgens DM, Coutinho K, Tsai W-T, Aziz K, Auer M, Tran PT, Bader JS, Ewald AJ. Twist1-induced dissemination preserves epithelial identity and requires E-cadherin. J Cell Biol. 2014;204(5):83956. https://doi.org/10.1083/jcb.201306088.

142. Han YL, Pegoraro AF, Li H, Li K, Yuan Y, Xu G, Gu Z, Sun J, Hao Y, Gupta SK, Li Y, Tang W, Kang H, Teng L, Fredberg JJ, Guo M. Cell swelling, softening and invasion in a three-dimensional breast cancer model. Nat Phys. 2019. https://doi.org/10.1038/s41567-019-0680-8.

143. Leggett SE, Patel M, Valentin TM, Gamboa L, Khoo AS, Williams EK, Franck C, Wong IY. Mechanophenotyping of 3D multicellular clusters using displacement arrays of rendered tractions. Proc Natl Acad Sci USA. 2020;117(11):5655-63. https://doi.org/10.1073/pnas.1918296117.

144. Ondeck MG, Kumar A, Placone JK, Plunkett CM, Matte BF, Wong KC, Fattet L, Yang J, Engler AJ. Dynamically stiffened matrix promotes malignant transformation of mammary epithelial cells via collective mechanical signaling. Proc Natl Acad Sci USA. 2019;116(9):3502-7. https ://doi.org/10.1073/pnas.1814204116.

145. Khoo AS, Valentin TM, Leggett SE, Bhaskar D, Bye EM, Benmelech S, Ip $\mathrm{BC}$, Wong IY. Breast cancer cells transition from mesenchymal to amoeboid migration in tunable three-dimensional silk-collagen hydrogels. ACS Biomater Sci Eng. 2019;5(9):4341-54. https://doi.org/10.1021/acsbi omaterials.9b00519.

146. Lee JY, Chang JK, Dominguez AA, Lee H-P, Nam S, Chang J, Varma S, Qi LS, West RB, Chaudhuri O. YAP-independent mechanotransduction drives breast cancer progression. Nat Commun. 2019;10(1):1848-9.

147. Ranamukhaarachchi SK, Modi RN, Han A, Velez DO, Kumar A, Engler AJ, Fraley SI. Macromolecular crowding tunes 3D collagen architecture and cell morphogenesis. Biomater Sci. 2019;7(2):618-33. https://doi. org/10.1039/C8BM01188E.

148. Rozenblatt-Rosen O, Regev A, Oberdoerffer P, Nawy T, Hupalowska A, Rood JE, Ashenberg O, Cerami E, Coffey RJ, Demir E, Ding L, Esplin ED, Ford JM, Goecks J, Ghosh S, Gray JW, Guinney J, Hanlon SE, Hughes SK, Hwang ES, lacobuzio-Donahue CA, Jané-Valbuena J, Johnson BE, Lau KS, Lively T, Mazzilli SA, Pe'er D, Santagata S, Shalek AK, Schapiro D, Snyder MP, Sorger PK, Spira AE, Srivastava S, Tan K, West RB, Williams EH. Human tumor atlas network: the human tumor atlas network: charting tumor transitions across space and time at single-cell resolution. Cell. 2020;181(2):236-49. https://doi.org/10.1016/j.cell.2020.03.053.

149. Schermelleh L, Ferrand A, Huser T, Eggeling C, Sauer M, BiehImaier O, Drummen GPC. Super-resolution microscopy demystified. Nat Cell Biol. 2019;21(1):72-84

150. Keikhosravi A, Bredfeldt JS, Sagar AK, Eliceiri KW. Second-harmonic generation imaging of cancer. Methods Cell Biol. 2014;123:531-46.

151. Ruskowitz ER, DeForest CA. Photoresponsive biomaterials for targeted drug delivery and 4D cell culture. Nat Rev Mater. 2018;3(2):1612-7.

152. Hussey GS, Dziki JL, Badylak SF. Extracellular matrix-based materials for regenerative medicine. Nat Rev Mater. 2018;3:159-73. https://doi. org/10.1038/s41578-018-0023-X.

153. Castelló-Cros R, Khan DR, Simons J, Valianou M, Cukierman E. Staged stromal extracellular 3D matrices differentially regulate breast cancer cell responses through PI3K and beta1-integrins. BMC Cancer. 2009;9(1):1-19. https://doi.org/10.1186/1471-2407-9-94.

154. Seo BR, Bhardwaj P, Choi S, Gonzalez J, Andresen Eguiluz RC, Wang K, Mohanan S, Morris PG, Du B, Zhou XK, Vahdat LT, Verma A, Elemento O, Hudis CA, Williams RM, Gourdon D, Dannenberg AJ, Fischbach C.
Obesity-dependent changes in interstitial ECM mechanics promote breast tumorigenesis. Sci Transl Med. 2015;7(301):301-130301130. https ://doi.org/10.1126/scitranslmed.3010467.

155. Fazio M, Ablain J, Chuan Y, Langenau DM, Zon LI. Zebrafish patient avatars in cancer biology and precision cancer therapy. Nat Rev Cancer. 2020;20(5):263-73. https://doi.org/10.1038/s41568-020-0252-3.

156. Ellenbroek SIJ, van Rheenen J. Imaging hallmarks of cancer in living mice. Nat Rev Cancer. 2014;14(6):406-18. https://doi.org/10.1038/nrc37 42.

157. Willetts L, Bond D, Stoletov K, Lewis JD. Quantitative analysis of human cancer cell extravasation using intravital imaging. In: Ursini-Siegel J, Beauchemin N, editors. The tumor microenvironment: methods and protocols. New York: Springer; 2016. p. 27-37.

158. Zhou ZN, Boimel PJ, Segall JE. Tumor-stroma: in vivo assays and intravital imaging to study cell migration and metastasis. Drug Discov Today Dis Models. 2011;8(2-3):95-112.

159. Fletcher CDM. Diagnostic histopathology of tumors. Amsterdam: Elsevier; 2021.

160. Roca-Cusachs P, Conte V, Trepat X. Quantifying forces in cell biology. Nat Cell Biol. 2017;19(7):742-51.

161. Sarrió D, Rodriguez-Pinilla SM, Hardisson D, Cano A, Moreno-Bueno G, Palacios J. Epithelial-mesenchymal transition in breast cancer relates to the basal-like phenotype. Cancer Res. 2008;68(4):989-97.

162. Leggett SE, Sim JY, Rubins JE, Neronha ZJ, Williams EK, Wong IY. Morphological single cell profiling of the epithelial-mesenchymal transition. Integr Biol. 2016;8:1133-44.

163. Boghaert E, Gleghorn JP, Lee K, Gjorevski N, Radisky DC, Nelson CM. Host epithelial geometry regulates breast cancer cell invasiveness. Proc Natl Acad Sci USA. 2012;109(48):19632-7.

164. Lee J, Abdeen AA, Hedhli J, Wycislo KL, Dobrucka IT, Fan TM, Dobrucki LW, Kilian KA. Melanoma topology reveals a stem-like phenotype that promotes angiogenesis. Sci Adv. 2017;3(10):1701350.

165. Guo M, Ehrlicher AJ, Jensen MH, Renz M, Moore JR, Goldman RD, Lippincott-Schwartz J, Mackintosh FC, Weitz DA. Probing the stochastic, motor-driven properties of the cytoplasm using force spectrum microscopy. Cell. 2014;158(4):822-32.

166. Gupta SK, Guo M. Equilibrium and out-of-equilibrium mechanics of living mammalian cytoplasm. J Mech Phys Solids. 2017;107:284-93.

167. Gupta SK, LiY, Guo M. Anisotropic mechanics and dynamics of a living mammalian cytoplasm. Soft Matter. 2019;15(2):190-9.

168. Moen E, Bannon D, Kudo T, GrafW, Covert M, Van Valen D. Deep learning for cellular image analysis. Nat Methods. 2019;16(12):1233-46.

169. van Helvert S, Storm C, Friedl P. Mechanoreciprocity in cell migration. Nat Cell Biol. 2018;20:8-20. https://doi.org/10.1038/s41556-017-0012-0.

170. Buttenschön A, Edelstein-Keshet L. Bridging from single to collective cell migration: a review of models and links to experiments. PLoS Comput Biol. 2020;16(12):1008411. https://doi.org/10.1371/journ al.pcbi.1008411.

171. Metzcar J, Wang Y, Heiland R, Macklin P. A review of cell-based computational modeling in cancer biology. JCO Clin Cancer Inform. 2019;3:1-13. https://doi.org/10.1200/CCl.18.00069.

172. Brabletz T. To differentiate or not-routes towards metastasis. Nat Rev Cancer. 2012;12(6):425-36.

173. Huber F, Boire A, López MP, Koenderink GH. Cytoskeletal crosstalk: when three different personalities team up. Curr Opin Cell Biol. 2015;32:39-47. https://doi.org/10.1016/j.ceb.2014.10.005.

174. Whipple RA, Balzer EM, Cho EH, Matrone MA, Yoon JR, Martin SS. Vimentin filaments support extension of tubulin-based microtentacles in detached breast tumor cells. Cancer Res. 2008;68(14):5678-88.

175. Yu M, Bardia A, Wittner BS, Stott SL, Smas ME, Ting DT, Isakoff SJ, Ciciliano JC, Wells MN, Shah AM, Concannon KF, Donaldson MC, Sequist LV, Brachtel E, Sgroi D, Baselga J, Ramaswamy S, Toner M, Haber DA, Maheswaran S. Circulating breast tumor cells exhibit dynamic changes in epithelial and mesenchymal composition. Science. 2013;339(6119):580-4.

176. Hendrix MJ, Seftor EA, Seftor RE, Trevor KT. Experimental co-expression of vimentin and keratin intermediate filaments in human breast cancer cells results in phenotypic interconversion and increased invasive behavior. Am J Pathol. 1997;150(2):483-95. 
177. Chu YW, Seftor EA, Romer LH, Hendrix MJ. Experimental coexpression of vimentin and keratin intermediate filaments in human melanoma cells augments motility. Am J Pathol. 1996;148(1):63-9.

178. Pastushenko I, Brisebarre A, Sifrim A, Fioramonti M, Revenco T, Boumahdi S, Van Keymeulen A, Brown D, Moers V, Lemaire S, De Clercq S, Minguijón E, Balsat C, Sokolow Y, Dubois C, De Cock F, Scozzaro S, Sopena F, Lanas A, D'Haene N, Salmon I, Marine J-C, Voet T, Sotiropoulou PA, Blanpain C. Identification of the tumour transition states occurring during EMT. Nature. 2018;556(7702):463-8.

179. Meyer SN, Galván JA, Zahnd S, Sokol L, Dawson H, Lugli A, Zlobec I. Coexpression of cytokeratin and vimentin in colorectal cancer highlights a subset of tumor buds and an atypical cancer-associated stroma. Hum Pathol. 2019;87:18-27. https://doi.org/10.1016/j.humpath.2019.02.002.

180. Ramaekers FC, Haag D, Kant A, Moesker O, Jap PH, Vooijs GP. Coexpression of keratin- and vimentin-type intermediate filaments in human metastatic carcinoma cells. Proc Natl Acad Sci USA. 1983;80(9):2618-22. https://doi.org/10.1073/pnas.80.9.2618.

181. Thomas PA, Kirschmann DA, Cerhan JR, Folberg R, Seftor EA, Sellers TA, Hendrix MJ. Association between keratin and vimentin expression, malignant phenotype, and survival in postmenopausal breast cancer patients. Clin Cancer Res. 1999;5(10):2698-703.

182. Aceto N, Bardia A, Miyamoto DT, Donaldson MC, Wittner BS, Spencer JA, Yu M, Pely A, Engstrom A, Zhu H, Brannigan BW, Kapur R, Stott SL, Shioda T, Ramaswamy S, Ting DT, Lin CP, Toner M, Haber DA, Maheswaran S. Circulating tumor cell clusters are oligoclonal precursors of breast cancer metastasis. Cell. 2014;158(5):1110-22.

183. Cheung KJ, Gabrielson E, Werb Z, Ewald AJ. Collective invasion in breast cancer requires a conserved basal epithelial program. Cell. 2013;155(7):1639-51.

184. Cheung KJ, Padmanaban V, Silvestri V, Schipper K, Cohen JD, Fairchild AN, Gorin MA, Verdone JE, Pienta KJ, Bader JS, Ewald AJ. Polyclonal breast cancer metastases arise from collective dissemination of keratin 14-expressing tumor cell clusters. Proc Natl Acad Sci USA. 2016;113(7):854-63.

185. Rhim AD, Mirek ET, Aiello NM, Maitra A, Bailey JM, McAllister F, Reichert M, Beatty GL, Rustgi AK, Vonderheide RH, Leach SD, Stanger BZ. EMT and dissemination precede pancreatic tumor formation. Cell. 2012;148(1-2):349-61.

186. Harper KL, Sosa MS, Entenberg D, Hosseini H, Cheung JF, Nobre R, Avivar-Valderas A, Nagi C, Girnius N, Davis RJ, Farias EF, Condeelis J, Klein CA, Aguirre-Ghiso JA. Mechanism of early dissemination and metastasis in Her2+ mammary cancer. Nature. 2016;540(7634):588-92.

187. Lourenco AR, Ban Y, Crowley MJ, Lee SB, Ramchandani D, Du W, Elemento O, George JT, Jolly MK, Levine H, Sheng J, Wong ST, Altorki NK, Gao D. Differential contributions of pre- and post-EMT tumor cells in breast cancer metastasis. Cancer Res. 2020;80(2):163-9.

188. Peinado H, Zhang H, Matei IR, Costa-Silva B, Hoshino A, Rodrigues G, Psaila B, Kaplan RN, Bromberg JF, Kang Y, Bissell MJ, Cox TR, Giaccia AJ, Erler JT, Hiratsuka S, Ghajar CM, Lyden D. Pre-metastatic niches: organspecific homes for metastases. Nat Rev Cancer. 2017;17(5):302-17.

189. Kim IS, Gao Y, Welte T, Wang H, Liu J, Janghorban M, Sheng K, Niu Y, Goldstein A, Zhao N, Bado I, Lo H-C, Toneff MJ, Nguyen T, Bu W, Jiang W, Arnold J, Gu F, He J, Jebakumar D, Walker K, Li Y, Mo Q, Westbrook TF, Zong C, Rao A, Sreekumar A, Rosen JM, Zhang XHF. Immuno-subtyping of breast cancer reveals distinct myeloid cell profiles and immunotherapy resistance mechanisms. Nat Cell Biol. 2019;21:1113-26.
190. Lo H-C, Xu Z, Kim IS, Pingel B, Aguirre S, Kodali S, Liu J, Zhang W, Muscarella AM, Hein SM, Krupnick AS, Neilson JR, Paust S, Rosen JM, Wang $\mathrm{H}$, Zhang XHF. Resistance to natural killer cell immunosurveillance confers a selective advantage to polyclonal metastasis. Nat Cancer. 2020;1(7):709-22.

191. Fischer KR, Durrans A, Lee S, Sheng J, Li F, Wong STC, Choi H, El Rayes T, Ryu S, Troeger J, Schwabe RF, Vahdat LT, Altorki NK, Mittal V, Gao D. Epithelial-to-mesenchymal transition is not required for lung metastasis but contributes to chemoresistance. Nature. 2015;527:472-6.

192. Zheng X, Carstens JL, Kim J, Scheible M, Kaye J, Sugimoto H, Wu C-C, LeBleu VS, Kalluri R. Epithelial-to-mesenchymal transition is dispensable for metastasis but induces chemoresistance in pancreatic cancer. Nature. 2015;527:525-30.

193. Navas T, Kinders RJ, Lawrence SM, Ferry-Galow KV, Borgel S, Hollingshead MG, Srivastava AK, Alcoser SY, Makhlouf HR, Chuaqui R, Wilsker DF, Konaté MM, Miller SB, Voth AR, Chen L, Vilimas T, Subramanian J, Rubinstein L, Kummar S, Chen AP, Bottaro DP, Doroshow JH, Parchment RE. Clinical evolution of epithelial-mesenchymal transition in human carcinomas. Cancer Res. 2020;80(2):304-18. https://doi.org/10.1158/00085472.CAN-18-3539.

194. Condeelis J, Weissleder R. In vivo imaging in cancer. Cold Spring Harb Perspect Biol. 2010;2(12):003848-003848.

195. Wang W, Wyckoff JB, Goswami S, Wang Y, Sidani M, Segall JE, Condeelis JS. Coordinated regulation of pathways for enhanced cell motility and chemotaxis is conserved in rat and mouse mammary tumors Cancer Res. 2007;67(8):3505-11. https://doi.org/10.1158/0008-5472. CAN-06-3714.

196. Giampieri S, Manning C, Hooper S, Jones L, Hill CS, Sahai E. Localized and reversible TGFbeta signalling switches breast cancer cells from cohesive to single cell motility. Nat Cell Biol. 2009;11(11):1287-96. https ://doi.org/10.1038/ncb1973.

197. Patsialou A, Bravo-Cordero JJ, Wang Y, Entenberg D, Liu H, Clarke M, Condeelis JS. Intravital multiphoton imaging reveals multicellular streaming as a crucial component of in vivo cell migration in human breast tumors. IntraVital. 2014;2(2):e25294. https://doi.org/10.4161/ intv.25294.

198. Beerling E, Seinstra D, de Wit E, Kester L, van der Velden D, Maynard C, Schäfer R, van Diest P, Voest E, van Oudenaarden A, Vrisekoop N, van Rheenen J. Plasticity between epithelial and mesenchymal states unlinks EMT from metastasis-enhancing stem cell capacity. Cell Rep. 2016;14(10):2281-8. https://doi.org/10.1016/j.celrep.2016.02.034.

199. Ilina O, Campanello L, Gritsenko PG, Vullings M, Wang C, Bult P, Losert W, Friedl P. Intravital microscopy of collective invasion plasticity in breast cancer. Dis Model Mech. 2018;11(9):034330. https://doi.org/10.1242/ dmm.034330.

200. Ilina O, Gritsenko PG, Syga S, Lippoldt J, La Porta CAM, Chepizhko O, Grosser S, Vullings M, Bakker G-J, Bult P, Zapperi S, Deutsch A, Friedl P. Cell-cell adhesion and 3D matrix confinement determine jamming transitions in breast cancer invasion. Nat Cell Biol. 2020;22:1103-15. https://doi.org/10.1038/s41556-020-0552-6.

\section{Publisher's Note}

Springer Nature remains neutral with regard to jurisdictional claims in published maps and institutional affiliations. 